\title{
Notch1 is a p53 target gene involved in human keratinocyte tumor suppression through negative regulation of ROCK1/2 and MRCK $\alpha$ kinases
}

\author{
Karine Lefort, ${ }^{1}$ Anna Mandinova, ${ }^{2}$ Paola Ostano, ${ }^{3}$ Vihren Kolev, ${ }^{2}$ Valerie Calpini, ${ }^{1}$ \\ Ingrid Kolfschoten, ${ }^{1}$ Vikram Devgan, ${ }^{2}$ Jocelyn Lieb, ${ }^{2}$ Wassim Raffoul, ${ }^{4}$ Daniel Hohl, ${ }^{5}$ Victor Neel, ${ }^{6}$ \\ Jonathan Garlick, ${ }^{7}$ Giovanna Chiorino, ${ }^{3}$ and G. Paolo Dotto ${ }^{1,2,8}$ \\ ${ }^{1}$ Department of Biochemistry, University of Lausanne, Epalinges CH-1066, Switzerland; ${ }^{2}$ Cutaneous Biology Research \\ Center, Massachusetts General Hospital, Charlestown, Massachusetts 02129, USA; ${ }^{3}$ Laboratory of Cancer \\ Pharmacogenomics, Fondo "Edo Tempia," Biella 13900, Italy; ${ }^{4}$ Department of Surgery, Centre Hospitalier Universitaire \\ Vaudois, Lausanne CH-1011, Switzerland; ${ }^{5}$ Department of Dermatology, Centre Hospitalier Universitaire Vaudois, Lausanne \\ CH-1011, Switzerland; ${ }^{6}$ Department of Dermatology, Massachusetts General Hospital, Boston, Massachusetts 02114, USA; \\ ${ }^{7}$ Division of Cancer Biology and Tissue Engineering, Tufts University Dental School, Boston, Massachusetts 02111, USA
}

Little is known about the regulation and function of the Notch1 gene in negative control of human tumors. Here we show that Notch1 gene expression and activity are substantially down-modulated in keratinocyte cancer cell lines and tumors, with expression of this gene being under p53 control in these cells. Genetic suppression of Notch signaling in primary human keratinocytes is sufficient, together with activated ras, to cause aggressive squamous cell carcinoma formation. Similar tumor-promoting effects are also caused by in vivo treatment of mice, grafted with keratinocytes expressing oncogenic ras alone, with a pharmacological inhibitor of endogenous Notch signaling. These effects are linked with a lesser commitment of keratinocytes to differentiation, an expansion of stem cell populations, and a mechanism involving up-regulation of ROCK1/2 and MRCK $\alpha$ kinases, two key effectors of small Rho GTPases previously implicated in neoplastic progression. Thus, the Notch1 gene is a p53 target with a role in human tumor suppression through negative regulation of Rho effectors.

[Keywords: Notch; p53; ROCK/MRCK; stem cells; squamous cell carcinoma; in vivo siRNA delivery]

Supplemental material is available at http://www.genesdev.org.

Received August 22, 2006; revised version accepted January 18, 2007.

Notch signaling is an important form of intercellular communication and plays a key role in cell fate determination and differentiation (Artavanis-Tsakonas et al. 1999). The biological function of this pathway is critically dependent on context-specific interactions with other signaling pathways, with possibly opposite roles in growth/differentiation of different cell types, at different developmental stages and/or under normal versus pathological conditions.

The Notch gene family encodes evolutionarily conserved type 1 transmembrane receptors that are activated by ligand binding and proteolytic cleavage, with release of the Notch intracellular domain (ArtavanisTsakonas et al. 1999). The best characterized "canonical" pathway of Notch activation involves translocation

\footnotetext{
${ }^{8}$ Corresponding author.
}

E-MAIL Gian-Paolo.Dotto@unil.ch; FAX 41-21-692-5705.

Article is online at http://www.genesdev.org/cgi/doi/10.1101/gad.1484707. of this molecule to the nucleus, where it associates with the DNA-binding protein CSL (CBF-1 or RBP-J $\kappa$ in mammalian cells), converting it from a repressor into an activator of transcription (Mumm and Kopan 2000; Lai 2002). While the cytoplasmic domain of Notch can directly bind to CBF-1, binding of Notch to a second ancillary protein, Mastermind-like 1 (MAML1) or related family members, is required for elevated levels of CSLdependent transcriptional activation (through recruitment of further transcription coactivators such as p300) (Petcherski and Kimble 2000; Wu et al. 2000; Oswald et al. 2001). A physical demonstration of a high-molecularweight Notch-CBF-1-Mastermind complex has been obtained (Fryer et al. 2002) as well as an elucidation of its structural organization (Nam et al. 2006; Wilson and Kovall 2006). Importantly, a 51-amino-acid peptide (MAM51) corresponding to the highly conserved N-terminal region of the MAML1 protein has been shown to function as a specific suppressor of Notch-CSL transcrip- 
tion, by competing for MAML1 binding to the complex and thereby preventing downstream transcriptional activation (Weng et al. 2003, 2004; Maillard et al. 2004; Balint et al. 2005).

The best characterized targets of Notch/CBF-1/ MAML-mediated activation are members of the HES and HERP families of basic helix-loop-helix (bHLH) transcriptional repressors (Iso et al. 2003). However, several other direct targets of Notch/CBF-1 transcription have been identified, which can be induced by Notch activation in a cell-type-specific manner. In particular, in mouse keratinocytes, the Notch pathway exerts growthinhibitory (Rangarajan et al. 2001) and tumor-suppressing functions (Nicolas et al. 2003; Proweller et al. 2006) that can be attributed to CBF-1 (RBP-JK)-dependent upregulation of $\mathrm{p} 21^{\mathrm{WAF} 1 / \mathrm{Cip} 1}$ with its consequent suppression of specific Wnt family members (Devgan et al. 2005). However, in human keratinocytes, Notch1 activation leads to little or no increase of $\mathrm{p} 21^{\mathrm{WAF} 1 / \mathrm{Cip} 1} \mathrm{ex}-$ pression, and causes more long-term suppression of growth and induction of differentiation, which can be attributed only in part to a "noncanonical" mechanism involving suppression of p63 expression (Nguyen et al. 2006). Little is known of the program of gene expression under specific Notch/CBF-1/MAML control in human keratinocytes.

Another major pathway that has been linked to control of keratinocyte cell fate determination, stem cell potential, and/or differentiation is that triggered by small GTPases of the Rho/Rac and CDC42 family (Xu et al. 2003; Benitah et al. 2005; Dotto and Cotsarelis 2005; Wu et al. 2006). Twenty small GTPases have been identified, which can be grouped in five distinct families (Jaffe and Hall 2005). The "on" or "off" state of these molecules is controlled by a large number of GTP exchange factors (GEFs) as well as GTPase-activating proteins (GAPs), with a positive and negative regulatory function, respectively, in response to several cues. The GTPases in "on" configuration activate, by direct binding, several effectors, in particular, protein kinases, with a cascade of downstream signaling events impinging on a variety of cellular processes (Jaffe and Hall 2005). Increased Rho signaling has also been positively connected with development and/or progression of tumors of various origins (Sahai and Marshall 2002). Importantly, no genetic mutations have been uncovered that are responsible for activation of this pathway in tumors, unlike those found with ras. Instead, increased expression of the Rho A or C GTPases and/or of their ROCK1/2 effectors has been described in several tumors, through as yet uncharacterized mechanisms (Sahai and Marshall 2002; Gomez del Pulgar et al. 2005). The MRCK $\alpha$ kinase, an effector of CDC42 with functional overlap with ROCK1/ 2 , has also been suggested to have a role in tumor progression (Benitah et al. 2004) and/or invasion (Wilkinson et al. 2005).

An inverse relationship exists between induction of differentiation and tumor development. Consistent with its role in maintaining lymphocyte stem cell populations, the role of Notch signaling in promoting human
T-cell leukemia is by now well demonstrated (Ellisen et al. 1991; Weng et al. 2004). A proto-oncogenic function of this pathway in human breast and ovarian carcinogenesis (Weijzen et al. 2002; Pece et al. 2004; Hopfer et al. 2005; Ayyanan et al. 2006) and in melanoma progression (Balint et al. 2005) is also emerging. In contrast, the possibility that Notch signaling plays an alternative tumorsuppressing function in human cancers of other types, where it can promote differentiation, has only been suggested on the basis of activated Notch1 overexpression studies (Linnoila et al. 2000; Shou et al. 2001; Sriuranpong et al. 2001; Talora et al. 2002; Qi et al. 2003). We report here that the Notch 1 gene is a p53 target in human keratinocytes with a role in tumor suppression of this cell type through negative regulation of the ROCK1/2 and MRCK $\alpha$ kinases.

\section{Results}

Notch1 is a p53 target gene down-modulated in human keratinocyte cancer cell lines and tumors

Notch signaling promotes commitment of human keratinocytes to differentiation and restricts their growth potential (Nguyen et al. 2006). Relative to normal human primary keratinocytes, immunoblot and RT-PCR analysis showed that Notch1 protein and mRNA were reduced in a panel of skin and oral squamous cell carcinoma (SCC) cell lines (Fig. 1A,B). Notch2 expression was also decreased, although less consistently (Fig. 1C). A similar reduction of Notch 1 expression was also found in a panel of skin SCCs relative to normal epidermis controls, with a parallel reduction in levels of the HES1 gene, a common target of the "canonical" Notch pathway (Fig. 1D,E). Reduced Notch1 expression was also confirmed by laser capture microdissection (LCM) and real-time RT-PCR analysis of additional skin SCCs versus surrounding normal epidermis (Fig. 1D, right panel).

For a more global approach, the same panel of skin SCCs examined above, plus two additional ones, were analyzed by cDNA microarray hybridization in parallel with normal epidermis controls, and the resulting differential gene expression profile was compared with the set of Notch-responsive genes that we previously identified in human primary keratinocytes after infection with an adenovirus expressing activated Notch1 (Nguyen et al. 2006). As shown in Figure 1F, many genes that are up- or down-regulated by Notch activation in keratinocytes exhibited an opposite pattern of expression in the tumors, including, as expected, HES1; other Notch targets like the OAS1 and IF144 interferon-responsive genes that we recently identified (Nguyen et al. 2006); and, as considered in detail further below, the ROCK2 and MRCK $\alpha$ (CDC42BPA) kinase genes.

Given the very frequent alterations of the p53 pathway in skin SCCs (Backvall et al. 2004), an attractive possibility was that the down-modulation of Notch signaling in these tumors is linked, at least in part, to compromised p53 function. RT-PCR analysis of an established p53 target gene with a tumor-suppressing function, Btg2 
Figure 1. Notch 1 expression and activity are down-modulated in keratinocyte SCC cell lines and tumors in parallel with p53 activity. (A) Primary human keratinocytes (HKC) were analyzed in parallel with keratinocyte-derived SCC cell lines (SCC011, SCC012, SCC13, and SCC022) by immunoblotting for Notch 1 and $\beta$-actin proteins. $(B, C)$ The same set of cells as in $A$ and the SCC09 cell line were analyzed for levels of Notch1 $(B)$ and Notch2 (C) mRNA by real-time RT-PCR. Values are in relative arbitrary units after $\beta$-actin normalization. $(D)$ Total RNA from surgically excised skin SCCs were analyzed in parallel with a set of three normal human epidermis controls (C) for Notch1 mRNA expression by real-time RT-PCR. Three other SCC samples obtained by LCM were similarly analyzed along with similarly obtained surrounding normal epidermis that was used as a reference control. The results are expressed as fold changes of expression of Notch1 mRNA levels in the tumors versus normal epidermis (after $\beta$-actin normalization). (E) The same samples from surgically excised skin SCCs and epidermis controls were analyzed for HES1 mRNA expression by real-time RT-PCR with the corresponding specific primers and $\beta$-actin normalization. $(F)$ Comparative analysis of genes with aberrant expression in skin SCCs versus Notch-responsive genes. A dendrogram obtained from agglomerative hierarchical clustering applied to a $105 \times 10$ gene per sample matrix using average link as linkage method and cosine correlation as metric. Genes modulated by activated Notch 1 in primary human keratinocytes were previously identified by microarray analysis of adenovirally infected cells (using an Affymetrix HG-U133Av2 platform) (Nguyen et al. 2006). The red and green name list refers to genes that are up- and down-regulated, respectively, by activated Notch1 (positive fold change and absolute Z-score higher than 1.96). The matrix columns refer to the eight SCC samples analyzed by RT-PCR above, plus two additional ones, whose gene expression was compared with the average expression of three normal epidermal tissues using the same platform (Affymetrix HG-U133Av2). As an overall measure of the general variation in gene expression among the normal control samples, for each gene with intensity $p$ value $<0.01$, the intensity standard deviation was divided by the intensity mean to obtain the gene coefficient of variation. Then the mean coefficient of variation (MCV) was used to measure the variability among normal samples. The MCV was equal to 0.6 if all genes or just the notch-responsive ones were considered, whereas it was equal to 0.7 if only the p53-responsive genes (as identified in $H$ ) were taken into consideration. A red-to-green gradient was used to indicate, for each gene, levels of up- or down-regulation in the individual tumors relative to normal controls. The corresponding gene symbols are indicated. The comprehensive log-ratio values of the matrix used for hierarchical clustering are provided as Supplementary Table 1. $(G)$ The same samples from surgically excised skin SCCs and epidermis controls were analyzed for Btg2 and p21 WAF1/Cip1 mRNA expression by real-time RT-PCR with the corresponding specific primers and $\beta$-actin normalization. $(H)$ Dendrogram obtained from agglomerative hierarchical clustering applied to a $111 \times 10$ gene per sample matrix using average link as linkage method and cosine correlation as metric. Genes modulated by knockdown of p53 by transfection of primary human keratinocytes with corresponding specific siRNA versus control oligonucleotides (at $3 \mathrm{~d}$ after transfection) were identified by microarray analysis with the Affymetrix (HG-U133AAv2) platform. The red and green name list refers to genes that were up- and down-regulated, respectively, by siRNA for $\mathrm{p} 53$ ( $p$ value $<0.01$ and absolute fold change $>2$ ). The matrix columns refer to the cluster analysis of the same SCC samples and normal epidermis examined in $A-H$. A red-to-green gradient was used to indicate, for each gene, levels of up- or down-regulation in the individual tumors relative to normal controls. The corresponding gene symbols are indicated. The comprehensive log-ratio values of the matrix used for hierarchical clustering is provided as Supplementary Table 2.

(Boiko et al. 2006), showed that its expression in SCCs was generally decreased (Fig. 1G). Expression of another "classical" p53 target, p21 WAF1/Cip1, was decreased in some SCCs but not in others (Fig. 1G), consistent with the complex regulation of this gene /Gartel and Tyner 1999) and its similarly reported heterogeneous expres- 
sion in tumors (e.g., see Erber et al. 1997). For a more global analysis of endogenous p53 targets in keratinocytes, we knocked down p53 expression by small interfering RNA (siRNA) transfection of these cells. Genes up- or down-regulated as a consequence of p53 suppression in human primary keratinocytes were compared with the expression profiles of skin SCCs versus normal epidermis. This analysis showed a concordance of genes that are similarly deregulated in the two cases (Fig. 1H). Among these was p53 itself, whose levels were significantly reduced in the tumors that we analyzed, as well as the Notch1 and HES1 genes, and ROCK2.

To more directly assess to what extent p53 function is linked to control of Notch1 gene expression, we compared the effects of knocked-down versus increased p53 expression. Primary human keratinocytes were either transfected with p53-specific siRNAs, as before, or treated with nutlin, an HDM2 inhibitor that causes increased levels of endogenous p53 (Vassilev et al. 2004). Notch1 expression (at RNA and protein levels) was induced as a result of increased p53, while it was downmodulated in cells with p53 knockdown (Fig. 2A). Infection with a recombinant adenovirus expressing wildtype p53 caused also an up-regulation of Notch1 expression not only in human primary keratinocytes, but, to an even greater extent, in SCC13 and SCC028 SCC cells, consistent with the reported loss of endogenous p53 activity in these cells (Fig. 2B; Boyle et al. 1993; Zhao et al. 2006).

Recent studies indicate that Notchl activation impairs intestinal goblet and enteroendocrine cell differentiation and may be a positive determinant of intestinal neoplasia development (Fre et al. 2005; van Es et al. 2005; Radtke et al. 2006). HCT116 is a well-characterized human colon carcinoma cell line with wild-type p53 (Bunz et al. 1998). In contrast to keratinocytes, knockdown of p53 in these cells did not down-modulate Notch1 expression (Fig. 2C), while conversely, increased p53 expression, by either adenoviral infection or nutlin treatment, led to no up-regulation (Fig. 2B,C).

Chromatin immunoprecipitation (ChIP) assays were used to assess whether the Notch 1 gene is a direct target of p53 and whether there are differences in binding of the p53 protein to the Notch1 promoter in keratinocytes versus colon carcinoma cells. Nucleotide sequence analysis indicated the presence of two putative p53-binding sites in the Notch1 promoter, at position $-3.55 \mathrm{~kb}$ as previously reported (Wei et al. 2006), and at $-0.8 \mathrm{~kb}$ from the translational start site (Fig. 2D). ChIP assays of human primary keratinocytes showed binding of endogenous p53 protein to both sites, with no binding to an unrelated internal sequence (Fig. 2D). No positive binding signal was obtained by similar ChIP assays with a cancer cell line (PC3) that lacks p53 (Zhao et al. 2006; data not shown). Quantitative ChIP assays by real-time PCR confirmed the results with human keratinocytes and showed even higher levels of p53 binding in HCT116 cells (Fig. 2E), indicating that the differential regulation of the Notch1 gene by p53 in the two cell types occurs downstream from promoter recognition and binding.
Inhibition of Notch signaling in human primary keratinocytes promotes aggressive SCC formation

To evaluate the functional consequences of decreased Notch signaling, as observed in the clinically occurring SCCs, we infected primary human keratinocytes with a retroviral vector expressing a 51-amino-acid peptide (MAM51) corresponding to the $\mathrm{N}$-terminal region (amino acids 13-74) of the MAML1 protein. This peptide competes for MAML1 binding to the Notch/CBF-1 complex, thereby preventing downstream transcription (Weng et al. 2003). As expected, the MAM51-expressing keratinocytes showed a significant reduction in "canonical" Notch signaling, as assessed by promoter activity assays with a Notch/CBF-1 reporter and real-time RTPCR for HERP1, an established endogenous Notch1 target gene (Fig. 3A,B). Besides CBF-1-dependent transcription, Notch activation can also induce the NF- $\mathrm{B}$ pathway through a separate mechanism unlikely to involve MAML1 function (Nguyen et al. 2006; Shin et al. 2006). In fact, MAM51 expression had no effect on NF- $\mathrm{B}$ signaling in keratinocytes under either basal or differentiating conditions, or after expression of oncogenic ras (Fig. 3C,D).

Subcutaneous injections of MAM51-expressing or control keratinocytes into mice caused no tumor formation. However, after infection with an oncogenic ras-transducing retrovirus, the MAM51-expressing keratinocytes gave rise to consistent tumor formation, while control cells expressing oncogenic ras alone produced either no tumors or only small nodules (Fig. 4A,B). This was observed with independent strains of primary keratinocytes, even with cells infected with the MAM51-expressing retrovirus for only a couple of passages prior to injection. The nodules formed by control keratinocytes expressing oncogenic ras alone had histological features of well-differentiated SCCs or benign keratinized cysts (Fig. 4C, top panels). In contrast, tumors formed by ras and MAM51-expressing keratinocytes were moderately to poorly differentiated carcinomas, with areas of spindle cell transformation (Fig. 4C, middle panels) positive for vimentin expression, and of large clear cells (Fig. 4C, bottom panels) positive for vimentin as well as carcino embryonic antigen (CEA) (data not shown). Besides growing into their initial hosts, these tumors were transplantable with a $80 \%$ efficiency of regrowth (four out of five transplants).

Activation of Notch receptors is critically dependent on $\gamma$-secretase cleavage at the cell membrane (ArtavanisTsakonas et al. 1999). Chemical inhibitors of $\gamma$-secretase activity can suppress endogenous Notch activity and have been proposed as possible therapeutic agents for cancers involving Notch activation (Miele et al. 2006). Our findings suggested that these same agents could have an opposite tumor-promoting function in keratinocyte tumor development. To assess this possibility, primary human keratinocytes infected with an oncogenic ras-transducing retrovirus were tested by skin-reconstitution grafting assays, under conditions that allow formation, under normal conditions, of well-stratified epi- 
Figure 2. Expression of the Notch1 gene is under positive p53 control in normal and SCC-derived keratinocytes. (A) Primary human keratinocytes were treated with Nutlin $(10 \mu \mathrm{M})$ or DMSO vehicle control for $24 \mathrm{~h}$, or transfected with siRNAs for p53 or scrambled siRNAs control for $48 \mathrm{~h}$. Induction and suppression of endogenous p53, respectively, were verified by immunoblotting. Notch 1 expression was also assessed by immunoblotting as well as real-time RT-PCR, using $\beta$-actin for internal normalization. (B) Primary human keratinocytes (HKC), alongside the squamous (SCC13, SCC028) and colon (HCT116) carcinoma cell lines, were infected with a recombinant adenovirus expressing wild-type p53 (Ad-p53) or GFP control (Ad-GFP) for $24 \mathrm{~h}$, followed by determination of Notch 1 mRNA levels by real-time RT-PCR as before. For each pair of cells, expression values are expressed relative to those of the Ad-GFP-infected controls. (C) HCT116 colon carcinoma cells were treated with Nutlin $(10 \mu \mathrm{M})$ or DMSO vehicle control for $24 \mathrm{~h}$, or transfected with siRNAs for p53 or scrambled siRNAs control for $48 \mathrm{~h}$. Induction and suppression of endogenous p53, respectively, were verified by immunoblotting. Notch1 expression was assessed by real-time RT-PCR using $\beta$-actin for internal normalization as in $A$ and $B$. (D) Primary human keratinocytes under growing conditions were processed for ChIP with antibodies specific for p53 or nonimmune IgG control followed by PCR amplification 50 cycles) of various regions of the Notch1 promoter as indicated in the schematic above. The sequences of the two predicted p53-binding sites (p53-A and p53-B) are, respectively, 5'-GGCCACGCCAAGCCATGGTCC-3' and 5'-AATCACGGCCAGGGATGTCTG-3'. "C" corresponds to an unrelated intervening sequence. Unprecipitated chromatin preparations were similarly analyzed and used as "input DNA" control. (E) Binding of endogenous p53 to its two predicted sites in the Notch1 promoter was quantified by ChIP assay and real-time PCR in human keratinocytes versus HCT116 colon carcinoma cells. The amount of precipitated DNA was calculated relative to the total input chromatin, and expressed as a percentage of the total according to the following formula (Frank et al. 2001): percentage total $=2^{\Delta \mathrm{Ct}} \times 5$, where $\Delta \mathrm{Ct}=\mathrm{Ct}$ (input) $-\mathrm{Ct}$ (immunoprecipitation), and Ct is the cycle threshold.

dermis (Dotto et al. 1989). Grafted mice were treated three times per week with either the $\gamma$-secretase inhibitor DAPT or DMSO vehicle alone. In control-treated mice, $H$-ras ${ }^{V 12}$-expressing keratinocytes produced a hyperplastic epithelium with only limited sites of invasion (Fig. 4D, top panels). In contrast, in mice treated with the $\gamma$-secretase inhibitor, there was aggressive tumor formation comparable with that caused by $\mathrm{H}$-ras ${ }^{\mathrm{V} 2}$ - and MAM51-coexpressing keratinocytes. Even in these cases, widespread areas of spindle cell transformation, with concomitant positive staining for vimentin and keratin expression, were observed (Fig. 4D, bottom panels).

\section{Inhibition of Notch signaling suppresses keratinocyte commitment to differentiation and expands populations with stem cell potential}

MAM51-expressing keratinocytes in culture exhibited no increased proliferation that could explain their in vivo tumorigenic behavior (Supplementary Fig. 1). Rather than enhanced growth of the total cell population, the tumor-promoting effects of decreased Notch signaling may be connected with decreased commitment to differentiation and expansion of keratinocyte subpopulations with stem cell potential, the likely targets of carcinogenesis (Perez-Losada and Balmain 2003). This possibility was assessed by several complementary assays.

Loss of keratinocyte adhesion to the substrate triggers important features of terminal differentiation, including irreversible withdrawal from the cell cycle (Watt et al. 1988). Gene expression analysis showed a substantial induction of Notch1 gene expression, as well as HES1 and HERP1 (Fig. 5A), in keratinocytes after various times of suspension culture. This was associated with an induction of endogenous p53 target genes like p21 ${ }^{\text {WAF1/Cip1, }}$ Gadd45 $\alpha$, and Btg2 (Fig. 5B). Both pathways were found to be functionally involved. In fact, after several hours of suspension culture, the fraction of keratinocytes that was able to reattach to the dish and resume growth was substantially increased by Notch suppression, via MAM51 expression (Fig. 5C) or DAPT treatment (data not shown). A protection against the irreversible commitment to differentiation was also observed with keratinocytes with p53 knockdown (Fig. 5D).

Notch activation in keratinocytes induces terminal differentiation markers of the suprabasal epidermal layers, like keratin 1 and involucrin, while it down-modulates integrins of the basal layer (integrin $\alpha 6 \beta 4$ ) (Rangarajan et al. 2001) as well as Wnt ligand family members (Devgan et al. 2005), which are positively connected 
A
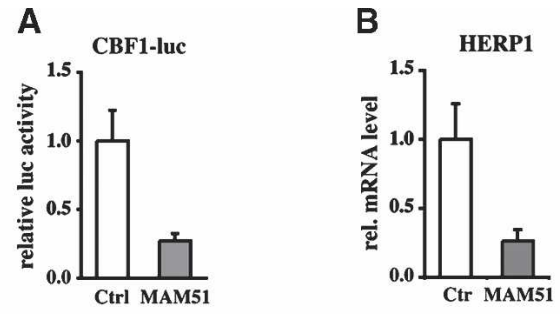

C
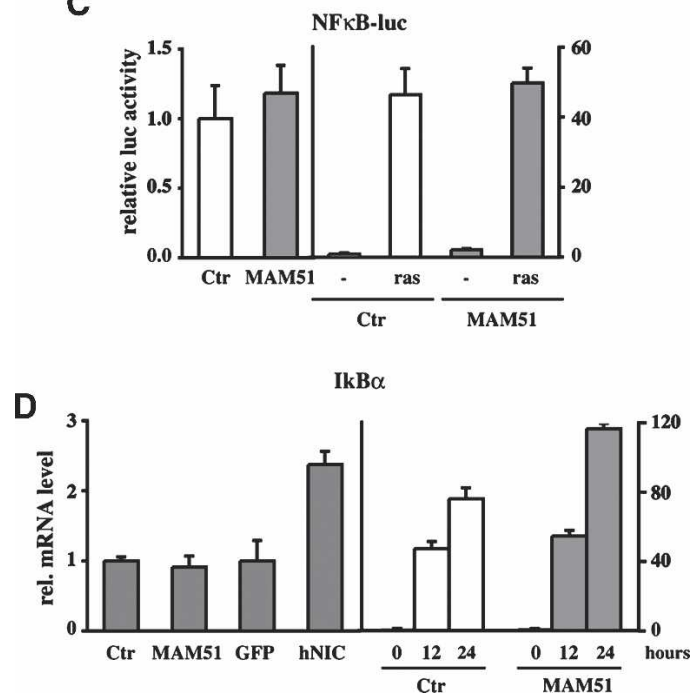

Figure 3. Expression of MAM51 in human primary keratinocytes inhibits specifically Notch/CBF-1-dependent transcription. (A) Primary human keratinocytes infected with a retrovirus expressing the MAM51 peptide or empty vector control (Ctr) were transfected with a luciferase reporter for Notch-CBF1 activity (CBF1-Luc; $1 \mu \mathrm{g}$ ) together with a Renilla minimal reporter for internal normalization $(0.05 \mu \mathrm{g})$. Promoter activity was measured $48 \mathrm{~h}$ after transfection. (B) MAM51-expressing and control keratinocytes were examined for levels of endogenous HERP1 expression by real-time RT-PCR analysis. Values are expressed as arbitrary units after normalization for GAPDH expression. (C, left panel) MAM51-expressing and control keratinocytes were transfected with a luciferase reporter for NF-кB activity $(1 \mu \mathrm{g})$ together with a Renilla minimal reporter for internal normalization $(0.05 \mu \mathrm{g})$. (Right panel) The same cells were transfected with a luciferase reporter for NF-кB activity plus/minus an expression vector for a $\mathrm{H}$-ras ${ }^{\mathrm{V} 12}$ oncogene (1 $\left.\mu \mathrm{g}\right)$. Promoter activity was measured $48 \mathrm{~h}$ after transfection. $(D$, left panel) Levels of endogenous IкB $\alpha$ expression, a direct target of NF-кB activation, were determined by real-time RT-PCR analysis of MAM51-expressing and control keratinocytes in parallel with primary human keratinocytes infected with an activated Notch1-expressing adenovirus (hNIC) or GFP control. Levels of endogenous IкB $\alpha$ expression were similarly determined in MAM51-expressing and control keratinocytes under basal conditions and after induction of differentiation by suspension culture for the indicated times (in hours).

with keratinocyte proliferation. Upon induction of differentiation, keratin 1 and involucrin expression were up-regulated in the MAM51-expressing keratinocytes to a lesser extent than in controls (Fig. 5E). Conversely, integrin $\alpha 6$ levels were increased in MAM51-expressing keratinocytes rather than suppressed as in the controls (Fig. 5F); integrin $\beta 4$ and Wnt7a levels were higher in MAM51-expressing keratinocytes already under growing conditions, and were less reduced with differentiation (Fig. 5F). In three-dimensional organotypic cultures, which recapitulate the normal vertical differentiation program occurring in vivo (Margulis et al. 2005), control keratinocytes produced a well-differentiated and stratified epidermis, while MAM51-expressing cells generated a lesser stratified epidermis with substantially reduced keratin 1 expression and up-regulation and aberrant suprabasal distribution of integrin $\alpha 6$ (Fig. 5G).

Clonogenic behavior of primary human keratinocytes provides a widely used assay for populations with high self-renewal potential (Rochat et al. 1994). In parallel with the above findings, after prolonged passaging, the fraction of keratinocytes with clonal growth capability was significantly higher in MAM51-expressing cultures than controls (Fig. 5H). This was accompanied by an expanded subpopulation with elevated integrin $\alpha 6$ (integrin $\left.\alpha 6^{\text {bright }}\right)$ and decreased CD71 expression (CD71 ${ }^{\mathrm{dim}}$ ), which are associated with putative stem cells (Fig. 5I; Li and Kaur 2005).

\section{ROCK1/2 and MRCK $\alpha$ are negative Notch target genes that are required for tumor development}

Little is known of the mechanisms involved in control of human keratinocyte stem cell potential by the "canonical" Notch/CBF-1 pathway. Another major pathway that has been recently linked to control of keratinocyte selfrenewal and/or differentiation is that triggered by small GTPases of the Rho/Rac and CDC42 family (Benitah et al. 2005; Grossi et al. 2005; Wu et al. 2006). Microarray analysis suggested that genes for the ROCK2 and MRCK $\alpha$ kinases, two major effectors of the RhoA and CDC42 GTPases, respectively (Ishizaki et al. 1996; Leung et al. 1998), are down-regulated by Notch activation in primary human keratinocytes with an opposite up-regulation in tumors (Fig. 1F). Real-time RT-PCR confirmed that expression of these genes is suppressed by activated Notch1 expression in human primary keratinocytes, and is similarly down-modulated by the "canonical" Notch effector HES1 (Fig. 6A). Several fully conserved HES-binding sites are present in the promoter region of the ROCK2 and MRCK $\alpha$ genes (Supplementary Fig. 2). Antibodies suitable for immunoprecipitation of the endogenous HES1 protein for analysis are not available. However, HES1 binds to a specific transcriptional corepressor, Tle-1 (Stifani et al. 1992), which can be readily immunoprecipitated by existing antibodies. ChIP assays with these antibodies showed that the Tle-1 protein is indeed associated with a predicted high-affinity HES1-binding region of the ROCK2 promoter, while no such association was detectable at a low-affinity, more downstream region (Fig. 6B).

Mirroring these results, expression of $\mathrm{MRCK} \alpha$, ROCK2, and the closely related ROCK1 gene was substantially up-regulated in the MAM51-expressing keratinocytes, while that of $\Delta \mathrm{Np} 63 \alpha$, which is controlled by 
Figure 4. Inhibition of Notch signaling in human keratinocytes promotes tumor formation. (A) Incidence of tumor formation by primary human keratinocytes expressing the MAM51 peptide plus oncogenic ras (MAM51) or control cells expressing oncogenic ras alone (Ctr). Human primary keratinocytes at passage 3 were infected with a MAM51- and GFP-expressing retrovirus (Weng et al. 2003) or an empty vector expressing only GFP. The efficiency of infection was $>90 \%$. After two more passages, MAM51-expressing and control keratinocytes were infected with an $\mathrm{H}$-ras ${ }^{\mathrm{V} 12}$ transducing retrovirus (LZRS-ras ${ }^{\mathrm{V} 12}$ ) (Lazarov et al. 2002) and, $16 \mathrm{~h}$ after infection, cells were admixed with Matrigel and injected subcutaneously in the suprascapular regions of NOD/SCID mice. To minimize individual animal variations, the same mice were injected in parallel with MAM51-expressing and control keratinocytes. The percentage and total number of tumors/injection at $6 \mathrm{wk}$ after injection are indicated. No tumor formation was detected by similar assays with MAM51-expressing and control keratinocytes without oncogenic ras expression (data not shown). (B) Weight of the pairs of individual tumors formed by ras-expressing MAM51 and control keratinocytes after parallel injections in the same mice. Shown are only the cases where control cells gave rise to detectable tumors. $(C)$ Histological and immunohistochemical analysis of tumors formed by control keratinocytes expressing oncogenic ras alone and keratinocytes expressing MAM51 together with oncogenic ras. For the latter tumors, shown are the widespread areas with morphological features of spindle cell (middle panels) and clear cell carcinoma formation (bottom panels). Tissues were processed for H\&E staining and immunohistochemical analysis with antibodies against pankeratins and vimentin as indicated. The anti-vimentin antibodies are human specific and do not cross-react with mouse tissue. In the middle panel are visible areas of local invasion, indicated by arrows. Bar, $90 \mu \mathrm{m} .(D)$ Histological and immunohistochemical analysis of grafts formed by human primary keratinocytes expressing oncogenic $\mathrm{H}$-ras ${ }^{\mathrm{V} 12}$ alone, injected subcutaneously into nude mice that were subsequently treated three times per week with either DMSO or DAPT $(1 \mathrm{mM})$ as indicated. Mice were sacrificed 4 wk after injections, and graft tissues were processed for $\mathrm{H} \& \mathrm{E}$ staining and immunostaining as above. In the bottom panels are visible areas of local invasion, indicated by arrows. Bar, 90 $\mu \mathrm{m}$.

Notch through a CBF1-independent mechanism (Nguyen et al. 2006), was not significantly modulated (Fig. 6C). Increased expression of ROCK1, ROCK2, and MRCK $\alpha$ was also observed in primary human keratinocytes after DAPT treatment (Fig. 6D). In parallel with these findings, expression of one or more of these genes was up-regulated in the skin SCCs that we examined (Fig. 6E) as well as in the SCC-derived cell lines (data not shown). Up-regulation of ROCK2 was also found by immunohistochemical analysis of additional clinically occurring SCCs, with similar results with experimental tumors formed by the MAM51 and ras keratinocytes (Fig. $6 \mathrm{~F}$, top and bottom panels, respectively).

Our finding that p53 is an upstream positive regulator
A

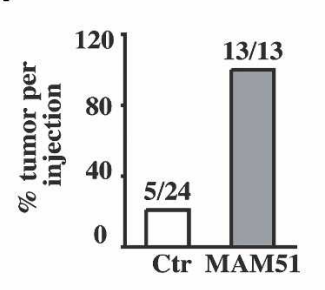

B

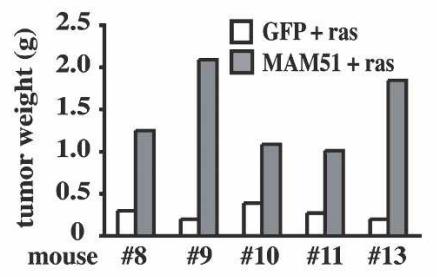

C $\& E$
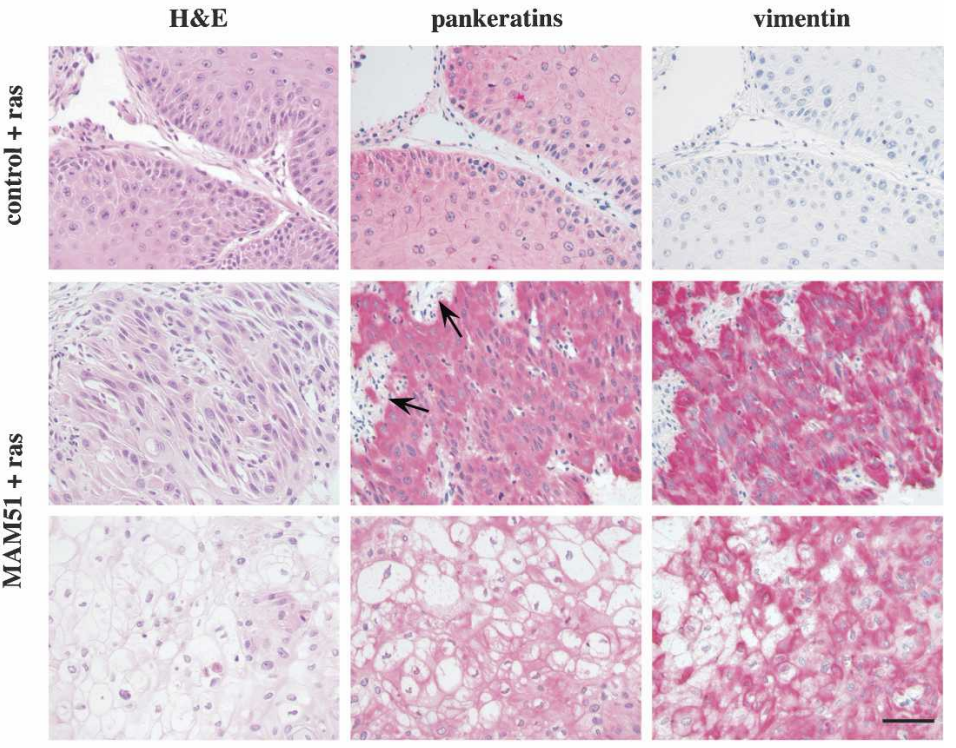

D
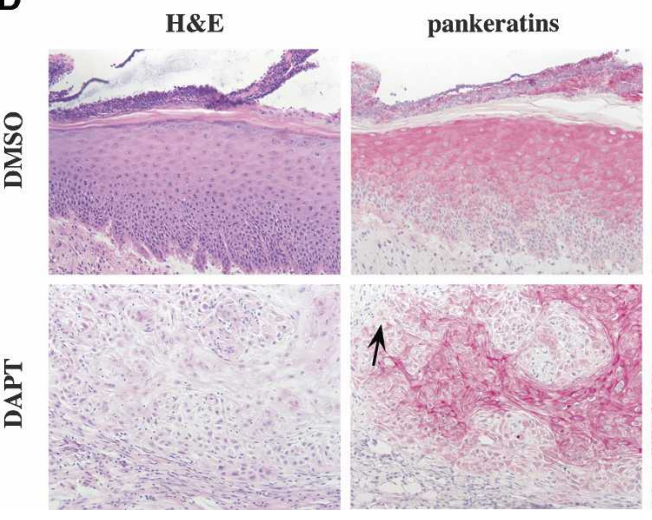

vimentin

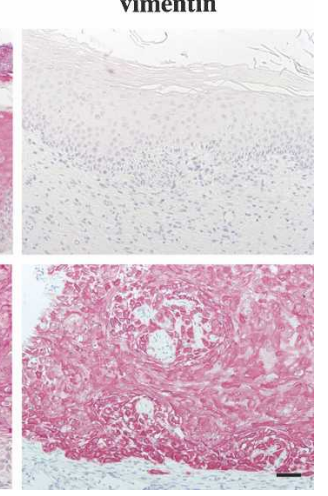

of Notch raised the interesting possibility that p53 may also control ROCK $1 / 2$ and MRCK $\alpha$ expression. Human keratinocytes with knockdown p53 expression exhibited a substantial increase of these genes, while, conversely, increased p53 expression caused a down-modulation of ROCK1/2 and MRCK $\alpha$ similar to that caused by activated Notch1 (Fig. 7, left and right panels, respectively). A block of endogenous Notch activity by DAPT did not counteract the suppressing effects of p53 on ROCK1 and 2 expression (Fig. 7D,E), while it partially prevented those on MRCK $\alpha$ (Fig. 7F), indicating that p53 controls these genes in a manner that is parallel and, in the case of MRCK $\alpha$, partially dependent on the Notch pathway.

To assess the functional significance of ROCK $1 / 2$ and 
A

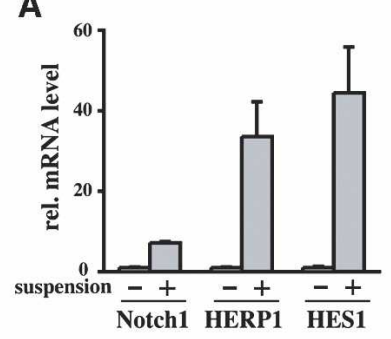

B
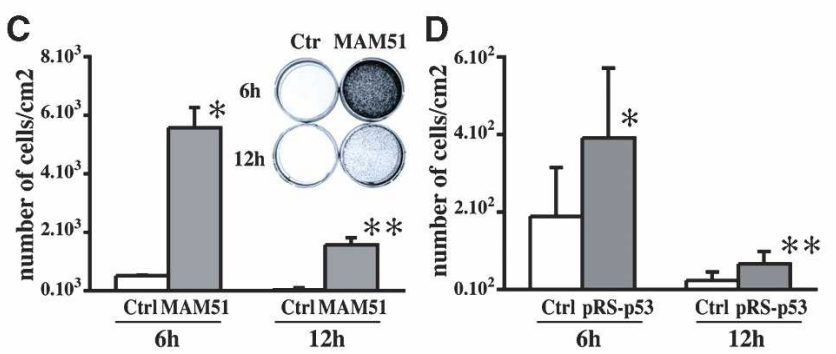

E
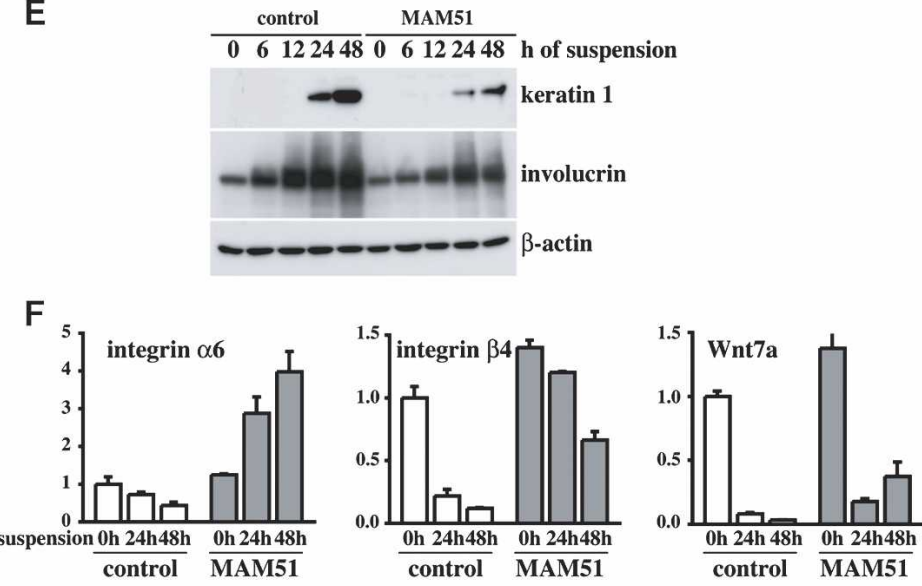

G
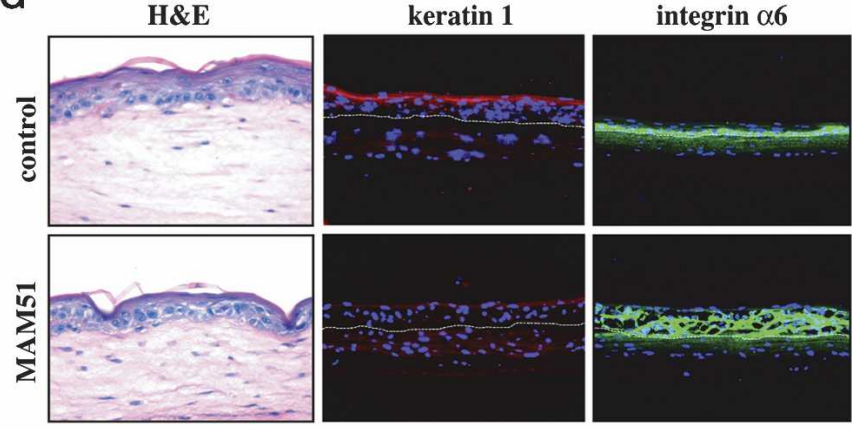

H

|
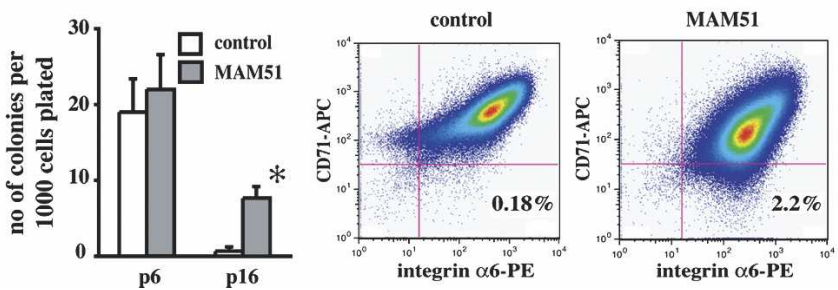

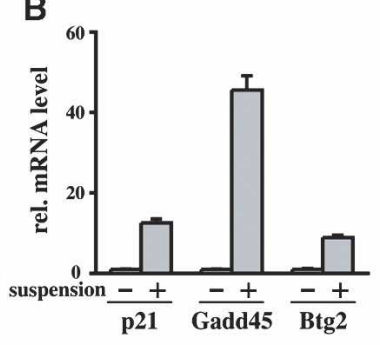

Figure 5. MAM51 expression in primary human keratinocytes suppresses commitment to differentiation and enhances stem cell populations. (A) Primary human keratinocytes were either kept under growing attached conditions or cultured in suspension on polyHEME-coated petri dishes, as previously described (Di Cunto et al. 1998), for 12-48 h. Cells were analyzed by real-time RT-PCR for Notch1, HERP1, and HES1 mRNA levels. There was a progressive increase of expression of these genes from the 12to 48 -h time point of suspension culture shown here. $(B)$ The same samples as in $A$ were analyzed for $\mathrm{p} 21, \operatorname{Gadd} 45 \alpha$, and Btg2 RNA levels by real-time RT-PCR. Even in this case, there was a progressive increase of expression of these genes from 12 to $48 \mathrm{~h}$ of suspension culture. $(C)$ MAM51-expressing and control keratinocytes were cultured in suspension for either 6 or $12 \mathrm{~h}$, followed by replating them $\left(3 \times 10^{5}\right.$ cells $/ 3.5-\mathrm{cm}$ dish $)$ and culturing for additional $5 \mathrm{~d}$. Shown are the stained dishes with the corresponding cell density. The statistical significance of the differences at 6 and $12 \mathrm{~h}$ was calculated by T-test; $\left({ }^{*}\right)$ $\left.p=0.003 ;{ }^{\star \star}\right) p=0.002$. $(D)$ Primary human keratinocytes infected with a short hairpin RNA (shRNA) retroviral vector for p53 (pRS-p53) or an empty vector control (Ctrl) (Brummelkamp et al. 2002) were cultured in suspension for either 6 or $12 \mathrm{~h}$, followed by replating them and culturing for an additional $5 \mathrm{~d}$ as in $C$. The statistical significance of the differences at 6 and $12 \mathrm{~h}$ was calculated by T-test; $\left.\left(^{\star}\right) p=0.09 ;{ }^{\star *}\right) p=0.07$. (E) MAM51-expressing and control keratinocytes were kept under growing conditions or induced to differentiate by suspension culture for the indicated times (in hours). Total protein extracts were analyzed by immunoblotting for keratin 1, involucrin, and $\beta$-actin as equal loading controls. (F) MAM51-expressing and control keratinocytes under growing conditions or induced to differentiate by suspension culture for 24 or $48 \mathrm{~h}$ were analyzed for integrins $\alpha 6$ and $\beta 4$ and Wnt7a mRNA levels by real-time RT-PCR. Values are expressed as arbitrary units after normalization for $\beta$-actin expression. Down-modulation of these genes by increased Notch signaling was confirmed by parallel experiments with primary human keratinocytes infected with adenoviruses expressing activated Notch 1 versus GFP control (data not shown). (G) Tridimensional organotypic cultures formed by MAM51-expressing (bottom panels) or control (top panels) keratinocytes grown on fibroblast-embedded dermal equivalents submerged in media for $4 \mathrm{~d}$ and for $10 \mathrm{~d}$ at the air-liquid interface were analyzed by $\mathrm{H} \& \mathrm{E}$ staining and immunofluorescence for keratin 1 and integrin $\alpha 6$. $(H)$ MAM51-expressing and control cultures were examined for number of keratinocytes with clonogenic potential by a NIH3T3 feeder assay. Keratinocytes were infected with the MAM51-expressing retrovirus and empty vector control at passage 3 . Cells at passages $6(\mathrm{p} 6)$ and $16(\mathrm{p} 16)$ were plated under sparse conditions $\left(10^{3} / 10-\mathrm{cm}\right.$ dish $)$ on triplicate dishes in the presence of mitomycin C-treated NIH3T3-J2 fibroblasts, and the number of macroscopic colonies was determined by rhodamine staining at 2 wk after plating. $T$-test calculations indicated that only the differences at passage 16 were statistically significant; $\left(^{*}\right)$ $p=0.004$. (I) MAM51-expressing and control keratinocyte cultures (passage 16) were examined for the population of cells with elevated integrin $\alpha 6$ and low CD71 expression, by FACS analysis. Shown are two-color fluorescence dot plots of control- (left panel) and MAM51-expressing (right panel) keratinocytes labeled simultaneously for integrin $\alpha 6$-PE and CD71APC. The percentage of $\alpha 6^{\text {bri }} \mathrm{CD} 71^{\text {dim }}$ obtained for each is indicated. 
Figure 6. The ROCK $1 / 2$ and MRCK $\alpha$ kinase genes are negative Notch targets up-regulated in experimental and clinically occurring SCC. (A) Primary human keratinocytes were infected with adenoviruses expressing activated Notch 1 (hNIC), HES1, or GFP control for $24 \mathrm{~h}$ and analyzed for levels of ROCK2 and MRCK $\alpha$ expression by real-time RT-PCR. Values are expressed in arbitrary units after normalization for $\beta$-actin expression. (Insert) Levels of ROCK2 protein expression by immunoblotting with the corresponding antibody and for $\beta$-actin as an equal loading control. (B) Primary human keratinocytes were processed for ChIP with an antibody against the HES1-associated Tle1 protein and purified rabbit IgGs as a nonimmune control. Real-time RT-PCR of two distinct regions of the ROCK2 gene containing, respectively, a high- and low-affinity HES1-binding site (HES-A and HES-B; see map above) were performed along with PCR of an HES1-binding site-free region, which was used as negative control (C). The results were normalized for "input" levels of unprecipitated chromatin DNA and expressed as arbitrary units. The nucleotide sequences of the predicted HES1-binding sites (at the indicated nucleotide positions relative to the translation initiation codon) are CACCAG for HES-A, and CAAGTG for HES-B. The HES-A site fully matches the sequence of the highaffinity HES1-binding sites (N-boxes), while the HES-B site matches the sequence of the low-affinity HES1-binding sites (class B sites) (Iso et al. 2003). (C) MAM51-expressing and control keratinocytes (Ctrl) at passage 5 were analyzed for levels of ROCK1, ROCK2, and MRCK $\alpha$ expression, in parallel with $\Delta \mathrm{N}$-p $63 \alpha$, by real-time RT-PCR as in $B$. (Insert) Levels of ROCK2 protein expression by immunoblotting with the corresponding antibody and for $\beta$-actin as equal loading control. (D) Primary human keratinocytes treated with DMSO or DAPT $(10 \mu \mathrm{M})$ for 24 $\mathrm{h}$ were analyzed for levels of ROCK1, ROCK2, and MRCK $\alpha$ expression by real-time RT-PCR as in C. (E) The same samples from surgically excised skin SCCs and epidermis controls examined in Figure 1, D, E, and G were analyzed for mRNA expression of ROCK1, ROCK2, and MRCK $\alpha$ by real-time RT-PCR with the corresponding specific primers, using primers for either the human 36B4 gene (Quan et al. 2002) or $\beta$-actin for normalization. (F) Three additional clinically occurring skin SCCs were analyzed for ROCK2 expression by immunohistochemistry with corresponding antibodies (top panels) in parallel with a similar analysis of tumors formed in NOD/SCID mice by primary human keratinocytes expressing H-ras ${ }^{\mathrm{V} 12}$ alone (control + ras) or together with MAM51 (MAM51 + ras) (bottom panels). A nonimmune negative control is also shown. Bar, $90 \mu \mathrm{m}$.
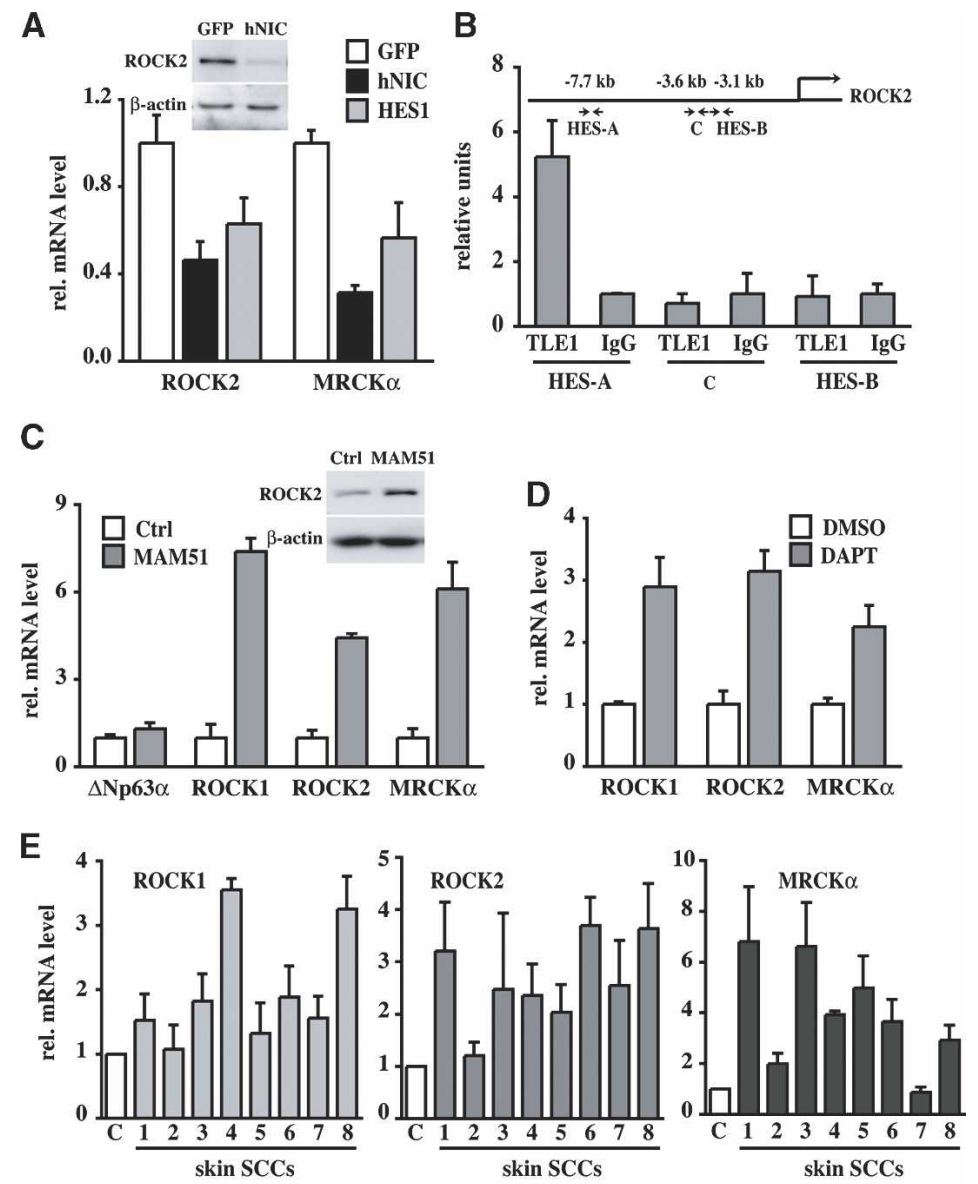

F
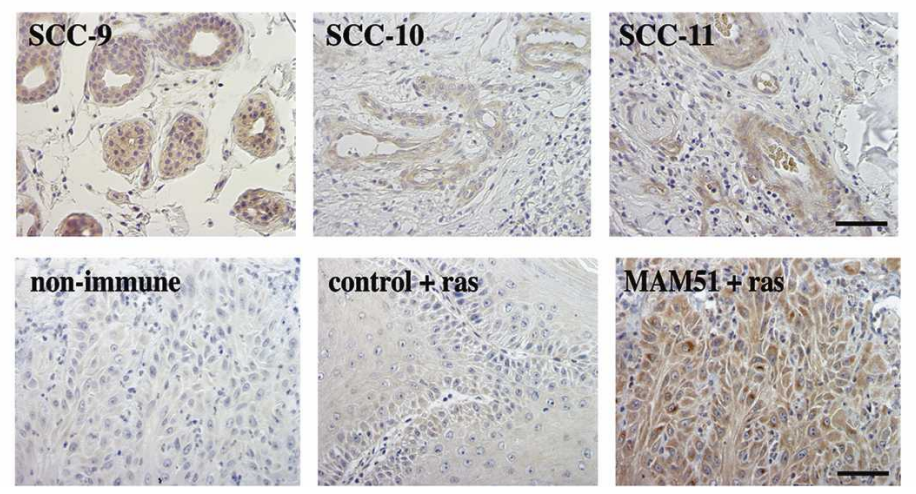

MRCK $\alpha$ up-regulation, we "knocked down" expression of these genes by siRNAs (Fig. 8A). Consistent with their functional redundancy (Wilkinson et al. 2005), only limited effects were observed by individual knockdown of these genes (data not shown). In contrast, the combined knockdown of these kinases reduced the elevated levels of integrins $\alpha 6$ and $\beta 4$ and Wnt7a expression of MAM51 keratinocytes (Fig. 8B), while enhancing differentiation of these cells (as assessed by keratin 1 expression) (Fig. $8 \mathrm{C})$. In parallel with their emerging role in cell cycle control and transcription, the best characterized function of ROCK $1 / 2$ and MRCK $\alpha$ kinases is in cell motility and invasion (Wilkinson et al. 2005). Consistent with our other findings, time-lapse microscopy showed a substantially increased mobility of MAM51-expressing versus control keratinocytes, such mobility being suppressed by ROCK1/2 and MRCK $\alpha$ knockdown (Fig. 8D). In parallel, MAM51 expressing keratinocytes exhibited also a much higher capability to migrate across a membrane filter barrier than control keratinocytes (Fig. 8E).

Recent advances have been made for in vivo siRNA delivery (Aigner 2006). Using this approach, we treated mice, which were either injected subcutaneously or grafted with the $H$-ras ${ }^{V 12} /$ MAM51 keratinocytes, with combined siRNAs for the ROCK $1 / 2$ and MRCK $\alpha$ kinases or scrambled siRNA control. As shown in Figure 9A, 
A

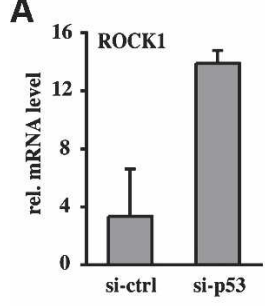

D

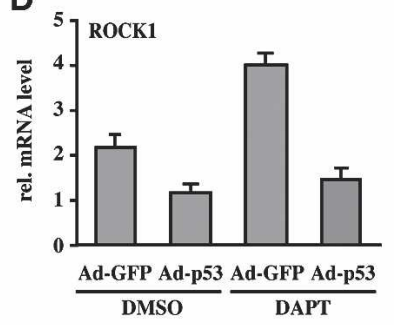

B

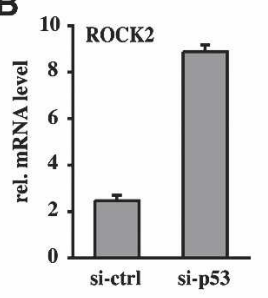

$\mathbf{E}_{0}$
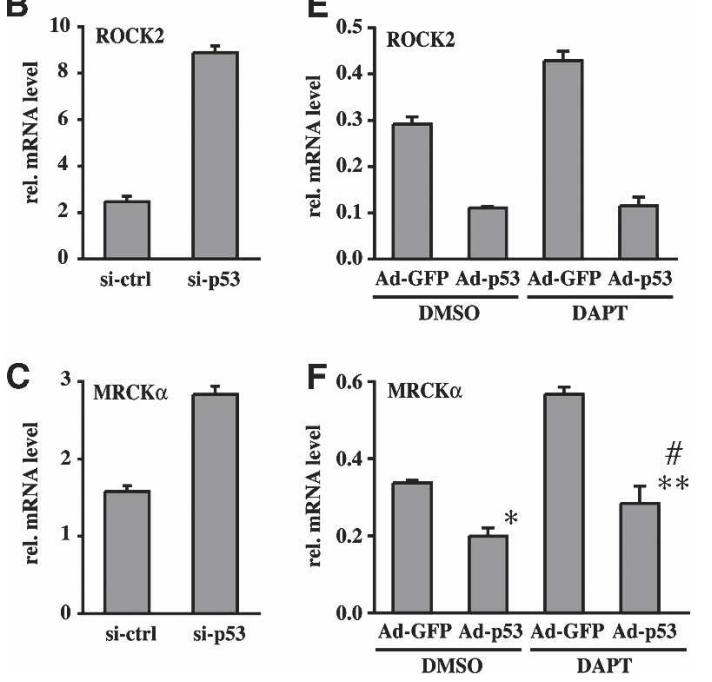

Figure 7. The ROCK $1 / 2$ and $M R C K \alpha$ kinase genes are negative p53 targets. $(A-C)$ Primary human keratinocytes were transfected with p53-specific siRNAs or siRNA controls and analyzed, at $48 \mathrm{~h}$ after transfection, for levels of ROCK1 $(A)$, ROCK2 $(B)$, and MRCK $\alpha(C)$ by real-time RT-PCR with $\beta$-actin for normalization. $(D-F)$ Primary human keratinocytes were infected with an adenovirus expressing wild-type p53 (Ad-p53) or a GFP control (Ad-GFP) for $2 \mathrm{~h}$ followed by treatment with DMSO or DAPT $(10 \mu \mathrm{M})$ for an additional $24 \mathrm{~h}$. Cells were analyzed for levels of ROCK1 $(D)$, ROCK2 $(E)$, and MRCK $\alpha(F)$ mRNA expression by real-time RT-PCR as in $A-C$. In $F$, the statistical significance of the differences between Ad-GFP- and Ad-p53-infected cells with either DMSO or DAPT treatment was calculated by $T$-test; $\left.\left.\left.\right|^{*}\right) p=0.002 ;\left.\right|^{\star *}\right) p=0.001$. T-test analysis was also used to evaluate the difference in MRCK $\alpha$ levels after Ad-p53 infection in DMSO- versus DAPT-treated cells; (\#) $p=0.03$.

treatment with the specific siRNAs caused a significant reduction of tumor formation in several animals, with small and well-differentiated lesions or even, in the case of grafted cells, a hyperplastic epithelium without overt signs of malignancy. The results of this set of experiments were further confirmed with a substantially larger number of animals (eight mice per group) for statistical validation of the results. Treatment with the ROCK $1 / 2$ and MRCK $\alpha$ siRNAs suppressed tumor growth over time (Fig. 9B), with a significant reduction of final tumor size (Fig. 9C).

\section{Discussion}

Tumor suppressor genes are classically defined as genes whose mutation or loss is required for tumor develop- ment (Hahn and Weinberg 2002). However, the importance of epigenetic mechanisms for down-modulation of negative growth regulatory genes and tumorigenesis is being increasingly recognized (Ting et al. 2006). We have shown here that expression of the Notch1 gene is significantly down-modulated in skin SCCs, in parallel with suppressed Notch activity. These findings are of likely functional significance as suppression of Notch signaling, by either genetic or pharmacological manipulations, is sufficient to elicit, together with oncogenic ras, oncogenic conversion of primary human keratinocytes.

Little is known of the upstream mechanisms controlling Notch1 expression. The p53 tumor suppressor gene is mutated or lost in a large fraction of human tumors, including skin SCCs (http://p53.free.fr) (Olivier et al. 2002), and, even when not mutated, p53 function can be compromised by secondary genetic and/or epigenetic events (Backvall et al. 2004). In human cell types where it promotes tumor formation, Notch signaling was reported to act upstream of p53, suppressing its function (Beverly et al. 2005; Mungamuri et al. 2006). In contrast, we have shown here that the Notch1 gene is a downstream positive target of p53 in both normal and cancerderived keratinocytes. A similar regulation of Notch1 expression by p53 occurs in prostate cancer cells, another cell type in which increased Notch signaling causes growth inhibition with associated tumor-suppressing effects (K. Lefort, P. Ostano, G. Chiorino, and G.P. Dotto, in prep.). In contrast, no such regulation was observed in HCT116 colon carcinoma cells, in parallel with the proposed tumor-promoting function of Notch signaling in this context (Radtke et al. 2006). This differential regulation occurs downstream from endogenous p53 binding to the Notch1 promoter and is likely due to an interplay with other cell-type-specific determinants of gene expression. In other ongoing work, we have found that activity of a reporter with $2 \mathrm{~kb}$ of the Notch 1 promoter is also under positive p53 control. However, together with the p53-binding region, we have identified another part of the Notch1 promoter, overlapping with the transcriptional start site, that is differentially active in primary keratinocytes versus cancer cells (C. Lambertini and G.P. Dotto, in prep.). It is also worth noting a putative p53-binding site that is highly conserved between mouse and human Notch1 promoters in their more upstream regions (at position -5339 from the ATG initiation site of the human gene). Thus, as with many other genes, transcriptional control of the Notch 1 gene is likely to result from p53 acting in concert with other key regulatory proteins at both proximal and distant sites.

Loss-of-function experiments were required to establish a possible tumor-suppressing function of Notch in human cells. Expression of the MAM51 peptide from the Mastermind-like 1 protein was previously used to suppress Notch signaling and inhibit tumorigenic behavior of acute T-cell leukemia cells as well as melanomas (Weng et al. 2003; Maillard et al. 2004; Balint et al. 2005). In sharp contrast, we have found that this same approach increased dramatically oncogenic transformation of pri- 
Lefort et al.
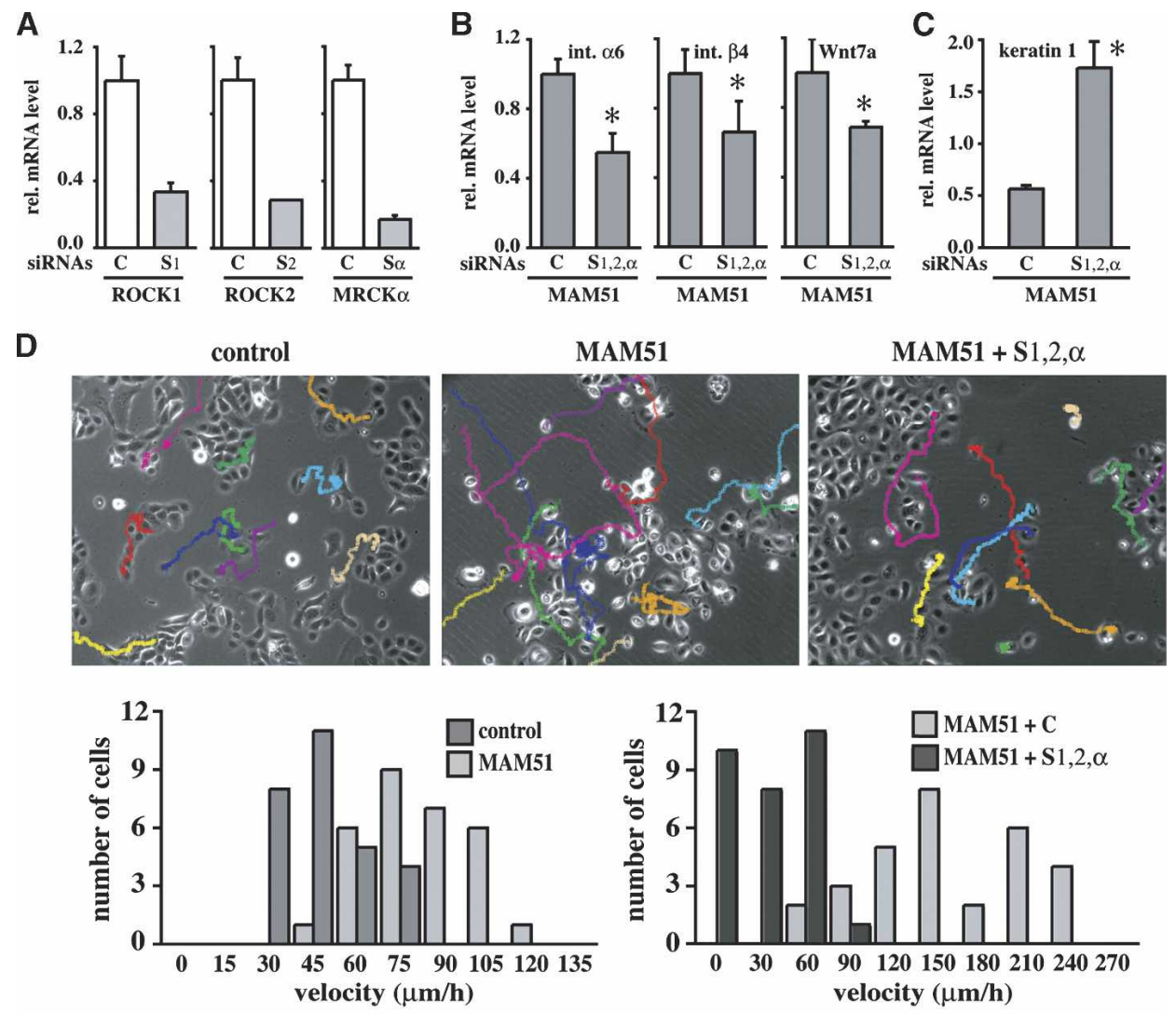

$\mathbf{E}$
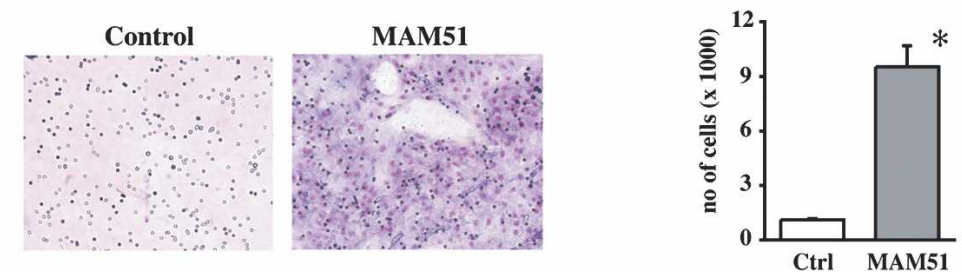

Figure 8. Increased ROCK $1 / 2$ and $\mathrm{MRCK} \alpha$ expression accounts for altered commitment to differentiation and increased motility of keratinocytes with suppressed Notch signaling. (A) Primary human keratinocytes were transfected with siRNAs (200 nM each) for the ROCK1, ROCK2, and MRCK $\alpha$ genes $\left(S_{1}, S_{2}, S_{\alpha}\right)$, alongside siRNA controls $(C)$, followed $72 \mathrm{~h}$ later by determination of their expression levels by real-time RT-PCR. Values are in arbitrary units after normalization for $\beta$-actin expression. (B) MAM51-expressing keratinocytes were transfected with siRNAs for ROCK1/2 and MRCK $\alpha$ genes $\left(\mathrm{S}_{1,2, \alpha}\right)$ followed $72 \mathrm{~h}$ later by determination of integrin $\alpha 6, \beta 4$, and Wnt7a expression by real-time RT-PCR. The statistical significance of the differences was calculated by T-test; integrin $\alpha 6$, $\left({ }^{\star}\right)$ $p=0.003$; integrin $\beta 4,\left(^{\star}\right) p=0.04$; Wnt7a, $\left(^{\star}\right) p=0.06$. (C) MAM51-expressing keratinocytes were transfected with siRNAs as in previous experiments and induced to differentiate by suspension culture for the last $48 \mathrm{~h}$ of the experiment. Keratin 1 expression was determined by real-time RT-PCR and expressed in arbitrary units after $\beta$-actin normalization; $\left({ }^{\star}\right) p=0.002$. $(D$, top panel) The motility of control and MAM51-expressing keratinocytes was measured by time-lapse microscopy over an 8-h period, with tracing of multiple individual cells. Motility was quantified by tracing the movement of 10 individual cells for each of three independent fields per condition, calculating for each cell the velocity of movement (in micrometers per hour). (Bottom panel, left) The number distribution of cells with different motility is indicated. A similar analysis was performed with MAM51-expressing keratinocytes transfected with siRNAs for the ROCK1/2 and MRCK $\alpha$ genes $\left(\mathrm{S}_{1,2, \alpha}\right)$ versus an siRNA control. (Bottom panel, right) Motility was quantified as before. (E) Control and MAM51-expressing keratinocytes were tested for their capability to migrate through a membrane filter barrier as specified in Materials and Methods. Briefly, cells in medium with low serum concentrations were added to the upper compartment of a Matrigel Invasion Chamber Kit, with the lower compartment containing medium with higher serum concentrations, as chemoattractant. (Left panel) After $24 \mathrm{~h}$ of incubation, nonmigratory cells were removed from the upper surface of the filter, and cells that had passed to the lower surface were fixed and stained. (Right panel) Assay quantification was achieved by post-labeling of cells that had crossed the filter with a fluorescent dye, and determining fluorescence intensity values. The assay was done in triplicate, with the indicated standard deviation. The statistical significance of the differences was calculated by $T$-test; $\left(^{\star}\right) p=0.002$. Similar results were obtained in a second independent experiment. 
A

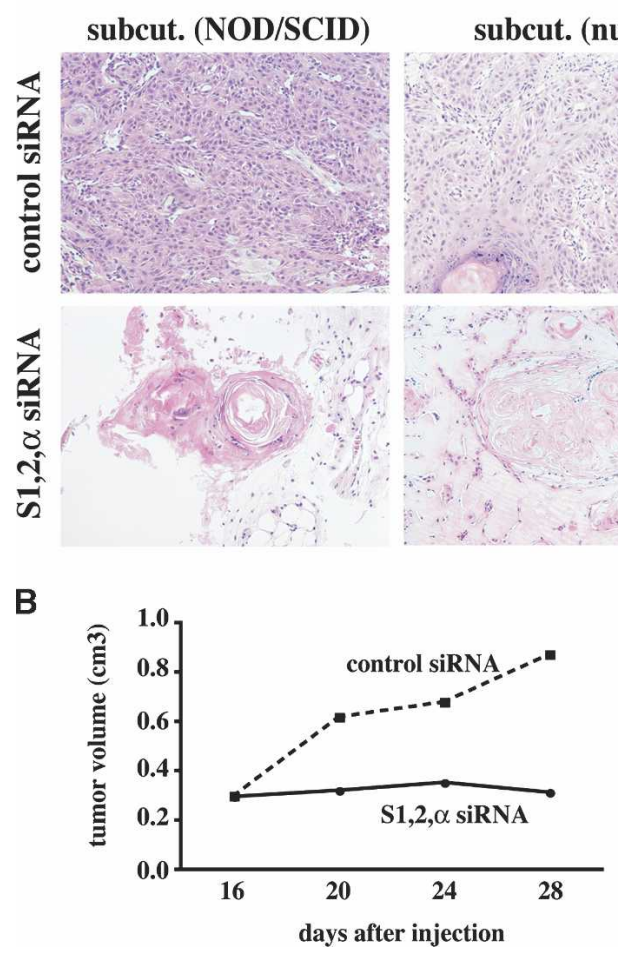

grafts

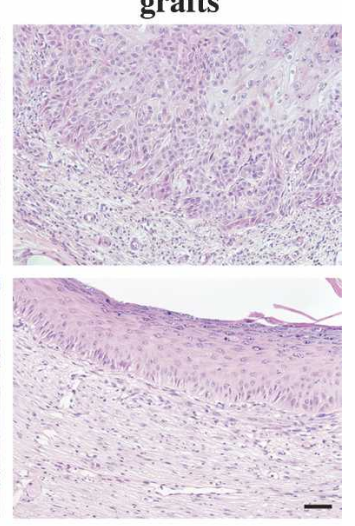

C

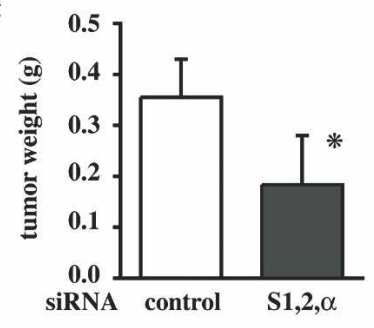

Figure 9. Increased ROCK $1 / 2$ and MRCK $\alpha$ expression accounts for altered commitment to differentiation and tumorigenicity of keratinocytes with suppressed Notch signaling. (A) $H$-ras $^{\text {V12 }}$ - and MAM51-expressing keratinocytes were injected subcutaneously into NOD/SCID or nude mice or grafted onto nude mice as indicated, followed by treatment every $3 \mathrm{~d}$ with either combined siRNAs for ROCK $1 / 2$ and MRCK $\alpha$ genes $\left(S_{1,2, \alpha}\right)$ or siRNA controls. Mice were sacrificed 4 wk later, and tissue samples were processed for $\mathrm{H} \& \mathrm{E}$ analysis. Bar, $90 \mu \mathrm{m}$. $(B, C)$ A second independent experiment with a larger cohort of NOD/SCID mice (eight per group) was injected with $\mathrm{H}$-ras ${ }^{\mathrm{V} 12}$ - and MAM51expressing keratinocytes followed by treatment with either combined siRNAs for ROCK $1 / 2$ and MRCK $\alpha$ genes $\left(S_{1,2, \alpha}\right)$ or siRNA controls as above. $(B)$ Tumor size was determined by the use of a caliper at the indicated days after injection, starting from the time the tumors became macroscopically measurable. (C) At the end of the experiment ( 1 mo after injection), mice were sacrificed, and tumors were carefully separated from surrounding tissue for weight determination. Shown is the average weight of tumors formed in mice treated with control versus specific siRNAs, together with standard deviation and statistical significance as determined by $T$ test; $\left(^{\star}\right) p=0.007$.

mary human keratinocytes by a $H$-ras ${ }^{v 12}$ oncogene, with formation of SCCs with widespread areas of epithelial mesenchymal transformation and clear cell cancer formation resembling those of aggressive tumors. Similar tumor-promoting effects were caused by pharmacological suppression of endogenous Notch activity by a $\gamma$-secretase inhibitor, which, in other cellular contexts, has been proposed as a possible anti-neoplastic agent (Miele et al. 2006).

Previous studies have reported oncogenic conversion of human primary keratinocytes by concomitant expression of oncogenic $H-r^{v 12}$ and suppression of NF- $\mathrm{kB}$, through a mechanism that promotes growth through TNF/JNK activity (Dajee et al. 2003; Zhang et al. 2004). Since Notch activation leads to induction of NF-кB (Nickoloff et al. 2002; Nguyen et al. 2006; Shin et al. 2006), an attractive possibility was that the tumor-suppressing function of Notch in keratinocytes is mediated by NF-кB. However, while suppressing "canonical" CBF1-dependent transcription, MAM51 expression did not affect NF-кB activity and had no direct growth-promoting effects on the total cell population. Telomerase activity in MAM51-expressing versus control keratinocytes was also not increased (data not shown). This is consistent with our other findings that Notch suppression, rather than causing an overall enhancement of growth, reduces the commitment of keratinocytes to differentiation with a relative increase, over time, of only a minor population of cells with high self-renewing clonogenic potential. As pointed out in a recent review (Merlo et al. 2006), acquisition of an "immortalized" cell phenotype is not necessarily a characteristic of the vast majority of cells in primary tumors. What is emerging instead is a consensus picture of "cancer stem cells," representing a minor, possibly slow-cycling population that gives rise to all other heterogeneous tumor cell populations. Besides deregulation of target stem cell populations, further genetic instability and mutational events are known to occur as tumors develop (Merlo et al. 2006). In the experimental situation that we have established, tumor formation is detectable as early as $2-3 \mathrm{wk}$ after injection of cells; it will be interesting to determine whether specific cell populations and additional genetic events are selected over time, in particular in the serial tumor transplants that we have initiated.

We previously showed that in mouse keratinocytes, Notch signaling exerts a growth-inhibitory and tumorsuppressing function that can be attributed to up-regulation of p21 $1^{\mathrm{WAF} / \mathrm{Cip} 1}$ expression (Rangarajan et al. 2001; Devgan et al. 2005). However, in human keratinocytes, Notch 1 activation leads to no increase of $\mathrm{p} 21^{\mathrm{WAF} / \mathrm{Cip} 1}$ expression and leads to down-regulation of p63 through a "noncanonical" CBF-1-independent pathway (Nguyen et al. 2006), which, as we have shown here, is unaffected by MAM51 expression. Nothing is known on the mechanisms whereby "canonical" Notch/CBF-1/MAML signaling restricts the growth potential of human keratinocytes and suppresses carcinogenesis. We have found that one such mechanism involves regulation of the ROCK1/2 and MRCK $\alpha$ kinases, two key effectors of 
RhoA and CDC42 GTPases, respectively (Ishizaki et al. 1996; Leung et al. 1998). Expression of both kinases is down-modulated in keratinocytes by activated Notch1, while it is up-regulated by MAM51 expression as well as DAPT treatment, and it is increased in keratinocyte-derived SCC cell lines and tumors. The promoter regions of the ROCK2 and MRCK $\alpha$ genes contain several fully conserved HES-binding sites, and their expression is suppressed by HES1, a classical Notch-CBF-1 target with transcription repressor function (Artavanis-Tsakonas et al. 1999|, to the same extent as activated Notch1. Importantly, expression of these genes is also under negative control of p53, through a parallel and, in the case of $\mathrm{MRCK} \alpha$, partially Notch-dependent mechanism. Biologically, ROCK1/2 and MRCK $\alpha$ have been recently implicated in tumor progression (Benitah et al. 2004) and invasion (Wilkinson et al. 2005). By a gene knockdown approach, we have found that up-regulation of these genes is required for the effects of Notch suppression in keratinocytes, including deregulated integrin and differentiation marker expression and increased cell motility. More importantly, our findings that the tumorigenicity of MAM51- and ras-expressing keratinocytes is impaired by the knockdown of the ROCK $1 / 2$ and MRCK $\alpha$ genes in vivo implicate these kinases as critical targets in control of human keratinocyte tumor formation.

\section{Materials and methods}

\section{Cell culture and viruses}

Culturing of primary human keratinocytes (Nguyen et al. 2006), suspension cultures (Watt et al. 1988), organotypic (Margulis et al. 2005) cultures, and clonogenicity assays (Rochat et al. 1994) were as previously reported. SCC011, SCC012, SCC022, and SCC028 cells were provided by Dr. J. Rocco (Massachusetts General Hospital, Boston, MA), and SCC13 cells were provided by Dr. J. Rheinwald (Brigham and Women's Hospital, Boston, MA), while other cells were from American Type Culture Collection (ATCC). LZRS-H-ras ${ }^{\mathrm{V} 12}$ (Dajee et al. 2003) and MSCVMAM51 (Andriani et al. 2003) retroviruses were provided by Drs. P. Khavari (Stanford University, Stanford, CA) and J. Aster (Brigham and Women's Hospital, Boston, MA), respectively. The Ad-p53 virus was from Dr. S. Lee (Massachusetts General Hospital, Charleston, MA), while the Ad-Notch1 virus was previously described (Rangarajan et al. 2001). Conditions for retrovirus and adenovirus production and infection were as previously reported (Rangarajan et al. 2001; Nguyen et al. 2006). The pRS-p53 vector was from Dr. Reuven Agami (The Netherlands Cancer Institute, Amsterdam, The Netherlands).

\section{Cell motility and migration assays}

Cell motility was measured by time-lapse microscopy, with cells under relatively sparse conditions in $60-\mathrm{mm}$ wells, and analyzed on an inverted Axiovert 100 microscope in a temperature- and $\mathrm{CO}_{2}$-controlled chamber, taking pictures every $3 \mathrm{~min}$ over an 8-h period.

Cell migration was measured using a Matrigel Invasion Chamber kit (BioCoat and FluoroBlok; Becton Dickinson Bioscience) according to the manufacturer's instructions. Cells $\left(1 \times 10^{5} / 200 \mu \mathrm{L}\right.$ in DMEM-0.1\% FCS $)$ were added to the upper compartment and incubated for $24 \mathrm{~h}$ at $37^{\circ} \mathrm{C}$. The lower compartment contained DMEM-5\% FCS as chemoattractant. After removal of nonmigratory cells from the upper surface of the filter, cells that had passed to the lower surface were fixed and stained with the Diff Quick Stain Kit. Quantification was achieved by post-labeling of migrated cells with a fluorescent dye, followed by fluorescence intensity determination.

\section{Subcutaneous tumorigenicity and keratinocyte grafting assays}

For in vivo tumorigenicity assays, control and MAM51-expressing keratinocytes were infected with the LZRS-H-ras ${ }^{\mathrm{V} 12}$ retrovirus and, $24 \mathrm{~h}$ after infection, were brought into suspension, admixed with Matrigel (BD Biosciences), and injected $\left(10^{6}\right.$ cells per injection) subcutaneously in NOD/SCID or nude mice. Tumors were dissected 4-6 wk later. Grafting assays were performed as previously described (Dotto et al. 1989). Briefly, keratinocytes were brought into suspension and injected $\left(5 \times 10^{6}\right.$ cells per injection) into a silicone transplantation chamber implanted onto the back of nude mice. For the in vivo DAPT treatment, this compound was injected subcutaneously at the site of grafting or, in some cases, directly into the transplantation chambers.

\section{Skin SCC samples}

Human SCC samples were obtained with Massachusetts General Hospital institutional approval as discarded material during Mohs micrographic surgery. For controls, normal skin was shaved very superficially with a \#15 scalpel blade with minimal dermal contamination. Alternatively, samples of SCC and normal epidermis were frozen in OCT and used for LCM using an AutoPix Automated Laser Capture Microdissection System, followed by one round of linear RNA amplification as we described previously (Mammucari et al. 2005).

\section{Quantitative real-time RT-PCR and microarray analysis}

Conditions for RNA preparation, real-time RT-PCR, and microarray analysis were as previously described (Mammucari et al. 2005). The list of gene-specific primers is provided in Supplementary Table 3.

\section{Immunodetection techniques}

Conditions for immunohistochemistry (Rangarajan et al. 2001), immunoblotting (Lefort et al. 2001), and FACS analysis (Li and Kaur 2005) were as described. The list of antibodies used for these studies is provided in the Supplemental Material.

\section{SiRNA transfection and in vivo delivery}

Cells were transfected as described (Nguyen et al. 2006) with $200 \mathrm{nM}$ siRNAs for validated human ROCK1, ROCK2, and $\operatorname{MRCK} \alpha / \beta$ (Dharmacon) in parallel with nonspecific control duplex VIII (Dharmacon), or with validated stealth RNA interference (RNAi) Duopak for p53 (Invitrogen) and corresponding Stealth RNAi control. For in vivo delivery, $200 \mathrm{pmol}$ of each siRNA (ROCK1, ROCK2, MRCK $\alpha / \beta$ ) or 600 pmol of the nonspecific control duplex VIII were complexed with Jet-PEI (Polyplus) as described (Grzelinski et al. 2006) and injected i.p. into mice every $3 \mathrm{~d}$ for $4 \mathrm{wk}$.

\section{ChIP assays}

These assays were carried out as previously described (Nguyen et al. 2006) with the modifications indicated in the Supplemen- 
tal Material. The primers of various regions of the human Notch1 promoter were 5'-AGCAGGGTACCCGCCACAGGA $-3^{\prime}$ and 5'-GACTCGGTGCAGGGACCATGG-3' (p53-A), 5'ACAATCCGTCCGCGAGGCACT-3' and 5'-AGGATCGATC GCCGCCAGACA-3' (p53-B), and 5'-ATTTGGCAAGAGGT GTG-3' and 5'-AGGCTGGGAGGGACCTAGGAC-3' (intervening sequence $\mathrm{C}$ ). The primers of various regions of the human ROCK2 promoter were 5'-CATGGACAAGATGCCAG GACG-3' and 5'-CAGGGTGGTGACTTCACGTAC-3' (HES-A), 5'-ATTGTGAGGACCCCGAGACAC-3' and 5'-ACTCCCCAG TTTGGATGTGCC-3' (HES-B), and 5'-GCTGAGAATGTAA ACGGGTAGCG-3' and 5'-ATTTTGCCTTGTTGCCCAGGC TG-3' (intervening sequence C).

\section{Acknowledgments}

We thank Drs. J. Aster, P. Khavari, R. Weinberg, S. Lee, R. Agami, J. Rocco, J. Rheinwald, and S. Stifani, for gifts of viruses, cells, and antibodies; Drs. C. Missero and C. Brisken for careful reading of the manuscript; and A. Ransijn, S. Streuli, and F. Burri for technical help. This work was supported by a grant from the Swiss National Foundation; NIH Grants AR39190, CA16038, and CA73796; a grant from the European Union (Epistem, Sixth Framework Program, LSHB-CT-2005-019067) to G.P.D.; and a grant by the Compagnia di San Paolo to G.C.

\section{References}

Aigner, A. 2006. Delivery systems for the direct application of siRNAs to induce RNA interference (RNAi) in vivo. $J$. Biomed. Biotechnol. 2006: 71659.

Andriani, F., Margulis, A., Lin, N., Griffey, S., and Garlick, J.A. 2003. Analysis of microenvironmental factors contributing to basement membrane assembly and normalized epidermal phenotype. J. Invest. Dermatol. 120: 923-931.

Artavanis-Tsakonas, S., Rand, M.D., and Lake, R.J. 1999. Notch signaling: Cell fate control and signal integration in development. Science 284: 770-776.

Ayyanan, A., Civenni, G., Ciarloni, L., Morel, C., Mueller, N., Lefort, K., Mandinova, A., Raffoul, W., Fiche, M., Dotto, G.P., et al. 2006. Increased Wnt signaling triggers oncogenic conversion of human breast epithelial cells by a Notch-dependent mechanism. Proc. Natl. Acad. Sci. 103: 3799-3804.

Backvall, H., Stromberg, S., Gustafsson, A., Asplund, A., Sivertsson, A., Lundeberg, J., and Ponten, F. 2004. Mutation spectra of epidermal p53 clones adjacent to basal cell carcinoma and squamous cell carcinoma. Exp. Dermatol. 13: 643-650.

Balint, K., Xiao, M., Pinnix, C.C., Soma, A., Veres, I., Juhasz, I., Brown, E.J., Capobianco, A.J., Herlyn, M., and Liu, Z.J. 2005. Activation of Notch 1 signaling is required for $\beta$-catenin-mediated human primary melanoma progression. J. Clin. Invest. 115: 3166-3176.

Benitah, S.A., Valeron, P.F., van Aelst, L., Marshall, C.J., and Lacal, J.C. 2004. Rho GTPases in human cancer: An unresolved link to upstream and downstream transcriptional regulation. Biochim. Biophys. Acta 1705: 121-132.

Benitah, S.A., Frye, M., Glogauer, M., and Watt, F.M. 2005. Stem cell depletion through epidermal deletion of Rac1. Science 309: 933-935.

Beverly, L.J., Felsher, D.W., and Capobianco, A.J. 2005. Suppression of p53 by Notch in lymphomagenesis: Implications for initiation and regression. Cancer Res. 65: 7159-7168.

Boiko, A.D., Porteous, S., Razorenova, O.V., Krivokrysenko,
V.I., Williams, B.R., and Gudkov, A.V. 2006. A systematic search for downstream mediators of tumor suppressor function of p53 reveals a major role of BTG2 in suppression of Ras-induced transformation. Genes \& Dev. 20: 236-252.

Boyle, J.O., Hakim, J., Koch, W., van der Riet, P., Hruban, R.H., Roa, R.A., Correo, R., Eby, Y.J., Ruppert, J.M., and Sidransky, D. 1993. The incidence of p53 mutations increases with progression of head and neck cancer. Cancer Res. 53: 44774480.

Brummelkamp, T.R., Bernards, R., and Agami, R. 2002. A system for stable expression of short interfering RNAs in mammalian cells. Science 296: 550-553.

Bunz, F., Dutriaux, A., Lengauer, C., Waldman, T., Zhou, S., Brown, J.P., Sedivy, J.M., Kinzler, K.W., and Vogelstein, B. 1998. Requirement for p53 and p21 to sustain G2 arrest after DNA damage. Science 282: 1497-1501.

Dajee, M., Lazarov, M., Zhang, J.Y., Cai, T., Green, C.L., Russell, A.J., Marinkovich, M.P., Tao, S., Lin, Q., Kubo, Y., et al. 2003. NF-кB blockade and oncogenic Ras trigger invasive human epidermal neoplasia. Nature 421: 639-643.

Devgan, V., Mammucari, C., Millar, S.E., Brisken, C., and Dotto, G.P. 2005. p21WAF1/Cip1 is a negative transcriptional regulator of Wnt4 expression downstream of Notch1 activation. Genes \& Dev. 19: 1485-1495.

Di Cunto, F., Topley, G., Calautti, E., Hsiao, J., Ong, L., Seth, P.K., and Dotto, G.P. 1998. Inhibitory function of p21Cip1/ WAF1 in differentiation of primary mouse keratinocytes independent of cell cycle control. Science 280: 1069-1072.

Dotto, G.P. and Cotsarelis, G. 2005. Developmental biology. Rac1 up for epidermal stem cells. Science 309: 890-891.

Dotto, G.P., Moellmann, G., Ghosh, S., Edwards, M., and Halaban, R. 1989. Transformation of murine melanocytes by basic fibroblast growth factor cDNA and oncogenes and selective suppression of the transformed phenotype in a reconstituted cutaneous environment. J. Cell Biol. 109: 3115-3128.

Ellisen, L.W., Bird, J., West, D.C., Soreng, A.L., Reynolds, T.C., Smith, S.D., and Sklar, J. 1991. TAN-1, the human homolog of the Drosophila notch gene, is broken by chromosomal translocations in T lymphoblastic neoplasms. Cell 66: 649661.

Erber, R., Klein, W., Andl, T., Enders, C., Born, A.I., Conradt, C., Bartek, J., and Bosch, F.X. 1997. Aberrant p21(CIP1/WAF1) protein accumulation in head-and-neck cancer. Int. J. Cancer 74: 383-389.

Frank, S.R., Schroeder, M., Fernandez, P., Taubert, S., and Amati, B. 2001. Binding of c-Myc to chromatin mediates mitogen-induced acetylation of histone $\mathrm{H} 4$ and gene activation. Genes \& Dev. 15: 2069-2082.

Fre, S., Huyghe, M., Mourikis, P., Robine, S., Louvard, D., and Artavanis-Tsakonas, S. 2005. Notch signals control the fate of immature progenitor cells in the intestine. Nature 435: 964-968.

Fryer, C.J., Lamar, E., Turbachova, I., Kintner, C., and Jones, K.A. 2002. Mastermind mediates chromatin-specific transcription and turnover of the Notch enhancer complex. Genes \& Dev. 16: 1397-1411.

Gartel, A.L. and Tyner, A.L. 1999. Transcriptional regulation of the p21(WAF1/CIP1) gene. Exp. Cell Res. 246: 280-289.

Gomez del Pulgar, T., Benitah, S.A., Valeron, P.F., Espina, C., and Lacal, J.C. 2005. Rho GTPase expression in tumourigenesis: Evidence for a significant link. Bioessays 27: 602-613.

Grossi, M., Hiou-Feige, A., Di Vignano, A.T., Calautti, E., Ostano, P., Lee, S., Chiorino, G., and Dotto, G.P. 2005. Negative control of keratinocyte differentiation by Rho/CRIK signaling coupled with up-regulation of KyoT1/2 (FHL1) expression. Proc. Nat1. Acad. Sci. 102: 11313-11318. 
Grzelinski, M., Urban-Klein, B., Martens, T., Lamszus, K., Bakowsky, U., Hobel, S., Czubayko, F., and Aigner, A. 2006. RNA interference-mediated gene silencing of pleiotrophin through polyethylenimine-complexed small interfering RNAs in vivo exerts antitumoral effects in glioblastoma xenografts. Hum. Gene Ther. 17: 751-766.

Hahn, W.C. and Weinberg, R.A. 2002. Modelling the molecular circuitry of cancer. Nat. Rev. Cancer 2: 331-341.

Hopfer, O., Zwahlen, D., Fey, M.F., and Aebi, S. 2005. The Notch pathway in ovarian carcinomas and adenomas. Br. J. Cancer 93: 709-718.

Ishizaki, T., Maekawa, M., Fujisawa, K., Okawa, K., Iwamatsu, A., Fujita, A., Watanabe, N., Saito, Y., Kakizuka, A., Morii, N., et al. 1996. The small GTP-binding protein Rho binds to and activates a $160 \mathrm{kDa}$ Ser/Thr protein kinase homologous to myotonic dystrophy kinase. EMBO J. 15: 1885-1893.

Iso, T., Kedes, L., and Hamamori, Y. 2003. HES and HERP families: Multiple effectors of the Notch signaling pathway. $J$. Cell. Physiol. 194: 237-255.

Jaffe, A.B. and Hall, A. 2005. Rho GTPases: Biochemistry and biology. Annu. Rev. Cell Dev. Biol. 21: 247-269.

Lai, E.C. 2002. Keeping a good pathway down: Transcriptional repression of Notch pathway target genes by CSL proteins. EMBO Rep. 3: 840-845.

Lazarov, M., Kubo, Y., Cai, T., Dajee, M., Tarutani, M., Lin, Q., Fang, M., Tao, S., Green, C.L., and Khavari, P.A. 2002. CDK4 coexpression with Ras generates malignant human epidermal tumorigenesis. Nat. Med. 8: 1105-1114.

Lefort, K., Rouault, J.P., Tondereau, L., Magaud, J.P., and Dore, J.F. 2001. The specific activation of gadd 45 following UVB radiation requires the POU family gene product $\mathrm{N}$-oct 3 in human melanoma cells. Oncogene 20: 7375-7385.

Leung, T., Chen, X.Q., Tan, I., Manser, E., and Lim, L. 1998. Myotonic dystrophy kinase-related Cdc42-binding kinase acts as a Cdc42 effector in promoting cytoskeletal reorganization. Mol. Cell. Biol. 18: 130-140.

Li, A. and Kaur, P. 2005. FACS enrichment of human keratinocyte stem cells. Methods Mol. Biol. 289: 87-96.

Linnoila, R.I., Zhao, B., DeMayo, J.L., Nelkin, B.D., Baylin, S.B., DeMayo, F.J., and Ball, D.W. 2000. Constitutive achaetescute homologue-1 promotes airway dysplasia and lung neuroendocrine tumors in transgenic mice. Cancer Res. 60: 4005-4009.

Maillard, I., Weng, A.P., Carpenter, A.C., Rodriguez, C.G., Sai, H., Xu, L., Allman, D., Aster, J.C., and Pear, W.S. 2004. Mastermind critically regulates Notch-mediated lymphoid cell fate decisions. Blood 104: 1696-1702.

Mammucari, C., Tommasi di Vignano, A., Sharov, A.A., Neilson, J., Havrda, M.C., Roop, D.R., Botchkarev, V.A., Crabtree, G.R., and Dotto, G.P. 2005. Integration of Notch 1 and calcineurin/NFAT signaling pathways in keratinocyte growth and differentiation control. Dev. Cell 8: 665-676.

Margulis, A., Zhang, W., and Garlick, J.A. 2005. In vitro fabrication of engineered human skin. Methods Mol. Biol. 289: 61-70.

Merlo, L.M., Pepper, J.W., Reid, B.J., and Maley, C.C. 2006. Cancer as an evolutionary and ecological process. Nat. Rev. Cancer 6: 924-935.

Miele, L., Miao, H., and Nickoloff, B.J. 2006. NOTCH signaling as a novel cancer therapeutic target. Curr. Cancer Drug Targets 6: 313-323.

Mumm, J.S. and Kopan, R. 2000. Notch signaling: From the outside in. Dev. Biol. 228: 151-165.

Mungamuri, S.K., Yang, X., Thor, A.D., and Somasundaram, K. 2006. Survival signaling by Notch1: Mammalian target of rapamycin (mTOR)-dependent inhibition of p53. Cancer
Res. 66: 4715-4724.

Nam, Y., Sliz, P., Song, L., Aster, J.C., and Blacklow, S.C. 2006. Structural basis for cooperativity in recruitment of MAML coactivators to Notch transcription complexes. Cell 124: 973-983.

Nguyen, B.C., Lefort, K., Mandinova, A., Antonini, D., Devgan, V., Della Gatta, G., Koster, M.I., Zhang, Z., Wang, J., di Vignano, A.T., et al. 2006. Cross-regulation between Notch and p63 in keratinocyte commitment to differentiation. Genes \& Dev. 20: 1028-1042.

Nickoloff, B., Qin, J., Chaturvedi, V., Denning, M., Bonish, B., and Miele, L. 2002. Jagged-1 mediated activation of notch signaling induces complete maturation of human keratinocytes through NF-кB and PPAR $\gamma$. Cell Death Differ. 9: 842 855.

Nicolas, M., Wolfer, A., Raj, K., Kummer, J.A., Mill, P., Van Noort, M., Hui, C.C., Clevers, H., Dotto, G.P., and Radtke, F. 2003. Notch1 functions as a tumor suppressor in mouse skin. Nat. Genet. 33: 416-421.

Olivier, M., Eeles, R., Hollstein, M., Khan, M.A., Harris, C.C., and Hainaut, P. 2002. The IARC TP53 database: New online mutation analysis and recommendations to users. Hum. Mutat. 19: 607-614.

Oswald, F., Tauber, B., Dobner, T., Bourteele, S., Kostezka, U., Adler, G., Liptay, S., and Schmid, R.M. 2001. p300 acts as a transcriptional coactivator for mammalian Notch-1. Mol. Cell. Biol. 21: 7761-7774.

Pece, S., Serresi, M., Santolini, E., Capra, M., Hulleman, E., Galimberti, V., Zurrida, S., Maisonneuve, P., Viale, G., and Di Fiore, P.P. 2004. Loss of negative regulation by Numb over Notch is relevant to human breast carcinogenesis. I. Cell Biol. 167: 215-221.

Perez-Losada, J. and Balmain, A. 2003. Stem-cell hierarchy in skin cancer. Nat. Rev. Cancer 3: 434-443.

Petcherski, A.G. and Kimble, J. 2000. Mastermind is a putative activator for Notch. Curr. Biol. 10: R471-R473.

Proweller, A., Tu, L., Lepore, J.J., Cheng, L., Lu, M.M., Seykora, J., Millar, S.E., Pear, W.S., and Parmacek, M.S. 2006. Impaired notch signaling promotes de novo squamous cell carcinoma formation. Cancer Res. 66: 7438-7444.

Qi, R., An, H., Yu, Y., Zhang, M., Liu, S., Xu, H., Guo, Z., Cheng, T., and Cao, X. 2003. Notch1 signaling inhibits growth of human hepatocellular carcinoma through induction of cell cycle arrest and apoptosis. Cancer Res. 63: 83238329.

Quan, T., He, T., Kang, S., Voorhees, J.J., and Fisher, G.J. 2002. Ultraviolet irradiation alters transforming growth factor $\beta /$ smad pathway in human skin in vivo. J. Invest. Dermatol. 119: 499-506.

Radtke, F., Clevers, H., and Riccio, O. 2006. From gut homeostasis to cancer. Curr. Mol. Med. 6: 275-289.

Rangarajan, A., Talora, C., Okuyama, R., Nicolas, M., Mammucari, C., Oh, H., Aster, J.C., Krishna, S., Metzger, D., Chambon, P., et al. 2001. Notch signaling is a direct determinant of keratinocyte growth arrest and entry into differentiation. EMBO I. 20: 3427-3436.

Rochat, A., Kobayashi, K., and Barrandon, Y. 1994. Location of stem cells of human hair follicles by clonal analysis. Cell 76: 1063-1073.

Sahai, E. and Marshall, C.J. 2002. RHO-GTPases and cancer. Nat. Rev. Cancer 2: 133-142.

Shin, H.M., Minter, L.M., Cho, O.H., Gottipati, S., Fauq, A.H., Golde, T.E., Sonenshein, G.E., and Osborne, B.A. 2006. Notch1 augments NF- $\mathrm{B}$ activity by facilitating its nuclear retention. EMBO J. 25: 129-138.

Shou, J., Ross, S., Koeppen, H., de Sauvage, F.J., and Gao, W.Q. 
2001. Dynamics of notch expression during murine prostate development and tumorigenesis. Cancer Res. 61: 7291-7297. Sriuranpong, V., Borges, M.W., Ravi, R.K., Arnold, D.R., Nelkin, B.D., Baylin, S.B., and Ball, D.W. 2001. Notch signaling induces cell cycle arrest in small cell lung cancer cells. Cancer Res. 61: 3200-3205.

Stifani, S., Blaumueller, C.M., Redhead, N.J., Hill, R.E., and Artavanis-Tsakonas, S. 1992. Human homologs of a Drosophila Enhancer of split gene product define a novel family of nuclear proteins. Nat. Genet. 2: 343.

Talora, C., Sgroi, D.C., Crum, C.P., and Dotto, G.P. 2002. Specific down-modulation of Notch1 signaling in cervical cancer cells is required for sustained HPV-E6/E7 expression and late steps of malignant transformation. Genes \& Dev. 16: 2252-2263.

Ting, A.H., McGarvey, K.M., and Baylin, S.B. 2006. The cancer epigenome-Components and functional correlates. Genes \& Dev. 20: 3215-3231.

van Es, J.H., van Gijn, M.E., Riccio, O., van den Born, M., Vooijs, M., Begthel, H., Cozijnsen, M., Robine, S., Winton, D.J., Radtke, F., et al. 2005. Notch $/ \gamma$-secretase inhibition turns proliferative cells in intestinal crypts and adenomas into goblet cells. Nature 435: 959-963.

Vassilev, L.T., Vu, B.T., Graves, B., Carvajal, D., Podlaski, F., Filipovic, Z., Kong, N., Kammlott, U., Lukacs, C., Klein, C., et al. 2004. In vivo activation of the p53 pathway by smallmolecule antagonists of MDM2. Science 303: 844-848.

Watt, F.M., Jordan, P.W., and O'Neill, C.H. 1988. Cell shape controls terminal differentiation of human epidermal keratinocytes. Proc. Nat1. Acad. Sci. 85: 5576-5580.

Wei, C.L., Wu, Q., Vega, V.B., Chiu, K.P., Ng, P., Zhang, T., Shahab, A., Yong, H.C., Fu, Y., Weng, Z., et al. 2006. A global map of p53 transcription-factor binding sites in the human genome. Cell 124: 207-219.

Weijzen, S., Rizzo, P., Braid, M., Vaishnav, R., Jonkheer, S.M., Zlobin, A., Osborne, B.A., Gottipati, S., Aster, J.C., Hahn, W.C., et al. 2002. Activation of Notch-1 signaling maintains the neoplastic phenotype in human Ras-transformed cells. Nat. Med. 8: 979-986.

Weng, A.P., Nam, Y., Wolfe, M.S., Pear, W.S., Griffin, J.D., Blacklow, S.C., and Aster, J.C. 2003. Growth suppression of pre-T acute lymphoblastic leukemia cells by inhibition of notch signaling. Mol. Cell. Biol. 23: 655-664.

Weng, A.P., Ferrando, A.A., Lee, W., Morris, J.P.T., Silverman, L.B., Sanchez-Irizarry, C., Blacklow, S.C., Look, A.T., and Aster, J.C. 2004. Activating mutations of NOTCH1 in human T cell acute lymphoblastic leukemia. Science 306: 269271.

Wilkinson, S., Paterson, H.F., and Marshall, C.J. 2005. Cdc42MRCK and Rho-ROCK signalling cooperate in myosin phosphorylation and cell invasion. Nat. Cell Biol. 7: 255-261.

Wilson, J.J. and Kovall, R.A. 2006. Crystal structure of the CSLNotch-Mastermind ternary complex bound to DNA. Cell 124: 985-996.

Wu, L., Aster, J.C., Blacklow, S.C., Lake, R., Artavanis-Tsakonas, S., and Griffin, J.D. 2000. MAML1, a human homologue of Drosophila mastermind, is a transcriptional co-activator for NOTCH receptors. Nat. Genet. 26: 484-489.

Wu, X., Quondamatteo, F., Lefever, T., Czuchra, A., Meyer, H., Chrostek, A., Paus, R., Langbein, L., and Brakebusch, C. 2006. Cdc42 controls progenitor cell differentiation and $\beta$-catenin turnover in skin. Genes \& Dev. 20: 571-585.

Xu, X., Lyle, S., Liu, Y., Solky, B., and Cotsarelis, G. 2003. Differential expression of cyclin D1 in the human hair follicle. Am. J. Pathol. 163: 969-978.

Zhang, J.Y., Green, C.L., Tao, S., and Khavari, P.A. 2004. NF-кB
RelA opposes epidermal proliferation driven by TNFR1 and JNK. Genes \& Dev. 18: 17-22.

Zhao, R., Xiang, N., Domann, F.E., and Zhong, W. 2006. Expression of p53 enhances selenite-induced superoxide production and apoptosis in human prostate cancer cells. Cancer Res. 66: 2296-2304. 


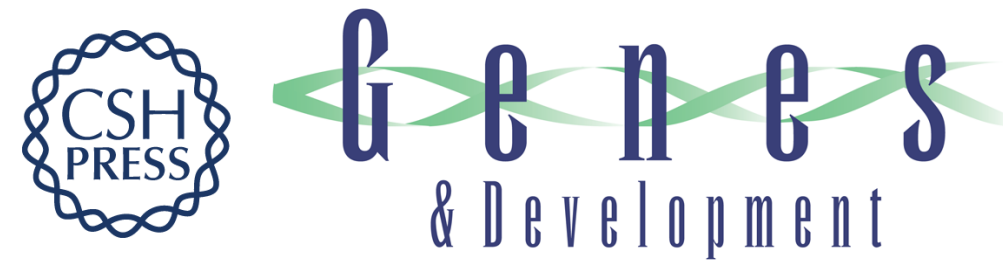

\section{Notch1 is a p53 target gene involved in human keratinocyte tumor suppression through negative regulation of ROCK1/2 and MRCK $\alpha$ kinases}

Karine Lefort, Anna Mandinova, Paola Ostano, et al.

Genes Dev. 2007, 21:

Access the most recent version at doi:10.1101/gad.1484707

Supplemental Material

References License

Email Alerting Service
http://genesdev.cshlp.org/content/suppl/2007/02/20/21.5.562.DC1

This article cites 81 articles, 36 of which can be accessed free at: http://genesdev.cshlp.org/content/21/5/562.full.html\#ref-list-1

Receive free email alerts when new articles cite this article - sign up in the box at the top right corner of the article or click here.

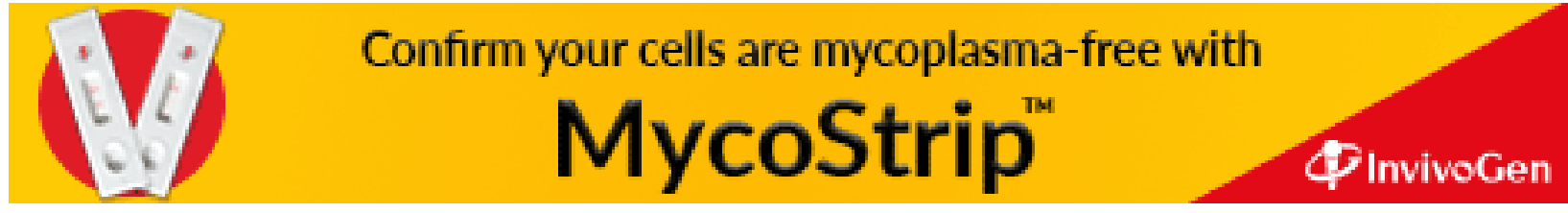

